\title{
Extended carbon footprint and emission transfer of world regions: With both primary and intermediate inputs into account
}

\author{
Xudong $\mathrm{Wu}^{\mathrm{a}, *}$, Chaohui $\mathrm{Li}^{\mathrm{b}, \mathrm{c}, \dagger}$, Jinlan $\mathrm{Guo}^{\mathrm{c}}$, Xiaofang $\mathrm{Wu}^{\mathrm{d}}$, Jing Meng ${ }^{\mathrm{e}, \mathrm{f}}$, \\ Guoqian Chen $^{\mathrm{c}, *}$ \\ ${ }^{a}$ School of Soil $\& 3$ Water Conservation, Beijing Forestry University, Beijing 100083, \\ China \\ ${ }^{b}$ Yenching Academy, Peking University, Beijing 100871, China \\ ${ }^{c}$ College of Engineering, Peking University, Beijing 100871, China \\ ${ }^{d}$ Economics School, Zhongnan University of Economics and Law, Wuhan 430073, China \\ ${ }^{e}$ The Bartlett School of Construction and Project Management, University College \\ London, London WC1E 7HB, UK \\ ${ }^{f}$ Cambridge Centre for Environment, Energy and Natural Resource Governance, \\ University of Cambridge, Cambridge CB2 3QZ, United Kingdom
}

\begin{abstract}
By combining the latest statistics for the global economy in 2015, this study as a continuation of our previous work (Wu et al., 2020) investigates the extended carbon footprint of world regions and the emission transfer via commodity trade, by including both primary and intermediate inputs into consideration. The extended carbon footprint of the United States is revealed to be one and a half times as much as that of China, while this ratio is accounted as three quarters in our previous work, due to that final consumption takes a much larger share of the gross domestic product in the United States
\end{abstract}

\footnotetext{
${ }^{\dagger}$ Chaohui Li contributed equally to this work.

${ }^{*}$ Corresponding authors

Email addresses: wuxudong@bjfu.edu.cn (Xudong Wu), gqchen@pku.edu.cn (Guoqian Chen) 
compared to the situation in China. $\mathrm{CO}_{2}$ emissions embodied in the primary inputs of the world economy are calculated to be equivalent to $42 \%$ of the emissions embodied in the genuine final consumption, highlighting the key role of capital goods in reallocating global carbon emissions. Moreover, emission transfer related with international commodity trade is explored, and the carbon trade links between major economies such as the United States, China, European Union, Russia, India and Japan are discussed in detail. In particular, the geographic and sectoral profiles for the carbon trade of the United States and China as two distinct economies are illustrated. It is revealed that Asia Pacific holds responsible for approximately half of the United States' carbon imports as well as China's carbon exports. Meanwhile, transport industry is taking up around one third of the United States' carbon exports while heavy and light industries totally dominate China's carbon exports. The outcome of this work may be supportive for providing more inclusive information regarding the establishment of global warming regimes, and may help us seek more informed policy choices and trade measures in global trade negotiations.

Keywords: Extended carbon footprint, emission transfer, primary inputs, trade patterns, latest statistics

\section{Introduction}

Widely believed as the main source accountable for anthropogenic climate 3 change, carbon dioxide emissions from fossil fuel burning have been a top fo- 
4 cus worldwide (Friedlingstein et al., 2010; Davis et al., 2011). According to 5 international energy agency (IEA, 2019), global $\mathrm{CO}_{2}$ emissions from fossil 6 fuel burning have increased by over $50 \%$ during the last 25 years, from 20521 7 million tons in 1990 to 32840 million tons in 2017. In a globally collaborative 8 effort to curb $\mathrm{CO}_{2}$ emissions, developed and developing countries are encour9 aged to share "common but differentiated responsibilities", as raised in the

10

United Nations Framework Convention on Climate Change (UNFCCC). A question is thus raised: By what accounting rule does the differentiation of responsibilities abide? This question has been to some extent addressed by International Panel on Climate Change (IPCC, 2006), regulating that the national carbon account should take inclusion of the carbon emissions and removals occurring in the sovereign territory of a country. Such accounting manner is called as territorial-based accounting in existing literature. Territorial-based accounting framework uses an onsite perspective to construct the carbon profile of nations, and it can be admitted that it is fully supportive to curbing emissions from the side of onsite carbon emitters.

Final-demand-based accounting as a parallel framework to territorialbased accounting focuses on the carbon footprint of a country/region and apportions the directly released emissions to those final products by treating final users' demand as the driving force of the economy (Feng et al., 2013, 2015). From the side of final users, this accounting framework seeks to quantify the emissions induced by final users' demand and emphasizes the role of international trade in reallocating carbon emissions between regions through 
the world's supply chain. According to Caldeira and Davis (2011), researches on emission transfer between regions under the final-demand-driven principle are to some extent opened up by Peters and Hertwich (2008), with the revelation that Annex B (developed) countries in Kyoto Protocol turn out to be net carbon importers. A number of global studies on carbon leakage through international commodity trade have afterwards encountered a blossom by sticking to the same accounting principle (Davis and Caldeira, 2010; Guan et al., 2008; Meng et al., 2016, 2018; Shao et al., 2018). For example, Davis et al. (2011) looked into the whole supply chain of embedded carbon emissions in 2004, reflecting that the international exchange of products holds responsible for $23 \%$ of global carbon emissions. Parallel to final-demand-based accounting, income-based accounting represents another kind of allocation ideology in dealing with a country/region's carbon footprint, by taking income beneficiaries as the economy's driver. Liang et al. (2017) constructed the income-based carbon profile for world regions, supported by the global multi-region input-output database. Meanwhile, household-consumptionand total-consumption-based accountings are emerging as two alternative frameworks for carbon emission assignment, with the household consumption and the total final consumption respectively identified as the genuine driver of the economy to be apportioned the emissions (Chen et al., 2019; Wu et al., 2019b). The accounting frameworks, no matter final-demand-, income, household-consumption-, total consumption-, or sales-based accountings reported in existing literatures (Kanemoto et al., 2012), could be catego- 
rized into the division of normative economics that reflects different opinions on which agents shall take the responsibility for the emissions directly discharged. For instance, Marques et al. (2012) compared three kinds of frameworks for carbon responsibility allocation, including production-based responsibility, consumption-based responsibility and income-based responsibility. The results show that different allocation schemes may produce quite different carbon budgets for a nation, which could be very useful in building up the carbon profile of a nation from various perspectives that complement each other, as also pointed out by Caldeira and Davis (2011). In the meanwhile, nevertheless, it is observed that while these accounting schemes try to capture different single segment of the world economy by a point-to-point linkage between direct carbon emissions and the specific agent chosen, not too much attention has been directed to the objective description of how the emissions travel along the intricate global supply chain in context of the segmentation of production activities (Chen et al., 2019).

With the world economy being turned into an economic entity, the spatial splitting-up of the production chain is witnessed (Mi et al., 2017; Zhang et al., 2017). The phenomenon as follows is highly probable: the extraction of fossil resources occurs in Region A; they are then exported to Region B and burned to support production of intermediate goods; the intermediate goods are further exported to Region C for reprocessing into finished products, which are ultimately exported to Region D to satisfy the needs of its local consumers. Taking iPhone (one of the best-selling products all over 
the world) for instance, a question might be asked: Where is an iPhone made? Neither is correct to say that iPhone is "made in China" nor "made in the United States". The answer might be "everywhere", or "made on the globe" (Apple, 2018; Macworld, 2017). The apple company outsources the manufacturing and assembly of the materials and components to more than 200 major manufacturers distributed worldwide, such as the Japan Display and Sharp, Samsung and LG Display in South Korea, Taiwan Semiconductor Manufacturing Company (TSMC), Foxconn and Pegatron in China, Bosch in Germany, etc. With such an intricate supply chain being formed, the global trade picture takes a different shape compared to old times when traded goods on the international markets are mainly finished products. Nowadays, semi-manufactured and re-exported products almost dominate the international trade market, the trade volume of which nearly doubles that of the products traded for final users' demand, as stated by Johnson and Noguera (2012). Correspondingly, the carbon emissions directly emitted in the production processes will be embodied in the products and then circulate with primary and semi-finished products along the global supply chains before departing from the economic system. Therefore, apart from the point-to-point assignment between direct emissions and the specific agents as adopted in normative accounting schemes, it is also important to give an objective description of the whole process of how carbon flows move along the global supply chain via international trade.

Embodiment accounting as a positive accounting framework follows the 
logic of positive economics (which settles questions of "what it is" instead of "what ought to be"), which could objectively clarify the whole circulating paths of carbon flows along the supply chains and formulate the associated carbon footprint of a nation/region. The history of embodiment accounting method could be traced back to 1970 s when Herendeen $(1973,1978)$ raised a conservation model of embodied energy to explore the circulation of energy use flows related with value flows. This method has enjoyed an extensive application to quantifying the carbon footprint of produced goods or services, and to tracking the associated carbon transfer at global (Chen and Chen, 2011), national (Zhang et al., 2018) as well as urban (Li et al., 2018) dimensions. It is noticed that Chen and Chen (2011) estimated the global carbon footprint and tracked the emission transfer between supra-national entities by dividing the world economy into three coalitions, namely G7, BRIC and the rest of the world. A subsequent study by Wu et al. (2020) moved a further step to probe into the international transfer of carbon flows in 2012 by differentiating intermediate and final trades, which revealed that carbon flows associated with intermediate products amount to a quantity much larger than those associated with final products.

The above-mentioned studies, by means of a positive accounting manner, contribute greatly to broadening our knowledge on carbon footprint of a country/region as well as on how carbon emissions are embodied in the manufactured goods and then travel along the world's value chains via trade before leaving out the economy to the society through final demand. It is observed 
that emissions embodied in the products used as final demand are regarded to take a departure from the economic system and no longer have any interaction with the economy in these studies. The truth is that, nevertheless, the products used for final demand may serve not only the consumptive purposes like household and government consumption, but also non-consumptive purposes like fixed capital formation. According to the concept of circular economy, the capital goods are to be going back into the economy as primary inputs and supporting the generation of goods and services (Bullard and Herendeen, 1975b; Wu et al., 2018). As a result, it seems to be reasonable that only the emissions embodied in those commodities used for genuine consumptive purposes are parting from the economic network and should be taken as the carbon footprint of a nation/region; emissions embodied in the large number of capital goods are to be taking a step into the economy as the social feedback. Recent works started to pay attention to the carbon feedback associated with capital goods by allocating carbon emissions embodied in capital goods to genuine final consumption. For instance, Södersten et al. (2018) endogenized capital in global multi-region input-output models and explored carbon footprints of some world regions. Cadarso et al. (2016) raised a concept of 'whole carbon footprint' and measured tourism's carbon footprint by taking consideration of both the consumption and investment of tourism sector. Chen et al. (2018) proposed a dynamic model to calculate global carbon footprints, by including capital stock change into consumption-based accounting of greenhouse gas emissions. Generally speaking, for some robust 
developing economies such as China, fixed capital formation holds a much bigger share of domestic final demand compared to the developed economies such as the United States. Therefore, if we include the social feedback and take the genuine final consumption instead of final demand as the sink of carbon emissions embodied in global supply chains, those economies with a high level of final consumption may turn out to have a larger carbon footprint. It is also noticed that these previous studies mostly focus on the responsibility allocation to final consumption with capital endogenized into multi-region input-output models, while less attention is paid to the circulating process of carbon flows via intermediate and final commodity trades along the supply chains of the world economy.

By an extension of the content of a previous work (Wu et al., 2020), this study seeks to utilize the latest statistics and analyze the extended carbon footprint of world regions, by directing enough attention to the intermediate feedback and social feedback. It should be noted that the term of extended carbon footprint is adopted in this paper to differentiate from the normal concept of carbon footprint. The picture on how carbon flows circulate in the global supply chains through commodity exchanges and afterwards sink into the products working for genuine consumptive purposes is depicted. The most recent statistics available for the world economy in 2015 are adopted to provide the latest empirical evidence. The transfer of carbon flows between world regions via international exchange of both intermediate and final products is illustrated, with the trade patterns of some main economies 
discussed. Details of carbon imports and exports for typical economies are also analyzed on sectoral and spatial dimensions. Policy implications are formulated to support effective measures in balancing economic growth and carbon emission mitigation.

\section{Methodology}

\subsection{Embodiment accounting}

Embodiment accounting originated from embodied energy accounting, which firstly appeared in an academic report by Herendeen (1973) as a supporting tool to explore the energy use of the United States economy and was then widely adopted to quantify the energy cost of goods or services (Bullard and Herendeen, 1975a). Later, by integrating the embodiment theory of systems ecology (Odum, 1983) into the energy balance model (Herendeen, 1973, 1978), Chen and his colleagues gave a generalization of embodied energy accounting to embodiment accounting of ecological elements, such as energy (Chen and Wu, 2017), water (Wu et al., 2019a) land (Wu et al., 2018), carbon emissions (Chen and Chen, 2011), mercury emissions (Li et al., 2017), exergy (Chen et al., 2010), etc. In our previous works, an embodiment accounting model supported by global multi-region input-output table has been established (Chen and Chen, 2011; Wu et al., 2020). For an economic sector within the world economy, the biophysical balance of carbon flows has been constructed in previous works as follows: the $\mathrm{CO}_{2}$ emissions embodied in the sectoral output are in magnitude equal to the onsite $\mathrm{CO}_{2}$ emissions 
of the economic sector plus the emissions embodied in intermediate inputs from all economic sectors into this sector. While the onsite $\mathrm{CO}_{2}$ emissions of the economic sector could be treated as emissions released into the environmental system, those embodied in intermediate inputs are internal feedbacks within the economy. Whereas, emissions embodied in the primary inputs have not been taken into consideration. For a sector's outputs, they are either used as inputs into economic sectors to facilitate production, or used as final demand to satisfy the needs of final consumers. In the global multiregion input-output table, the sub-categories under final demand are household consumption, consumption of non-profit institutions serving households, government consumption, fixed capital formation, and inventory change \& valuables acquisition. Products that are used to satisfy household consumption, non-profit institutions' consumption, and government consumption are "consumed" and do not further go back into the economic system. While for the products used as fixed capital formation, inventory change and valuables acquisition, they are generally referred to as "capital good" and do not represent the end of the economic chains. They are bound to re-enter the economic system (in the form of primary inputs) as the support from the society to promote producing activities.

Therefore, an embodiment accounting model supported by global multiregion input-output table is further developed on basis of the one raised in our previous studies (Chen and Chen, 2011; Wu et al., 2020), following the biophysical balance of carbon cost regulating that the inputs equal the 
outputs in terms of carbon emissions. In this newly-raised model, carbon emissions embodied in the primary inputs, i.e. external feedback from the society into the economy, are taken into account. The balance of carbon flows for one economic sector is established as follows: the $\mathrm{CO}_{2}$ emissions embodied in the sectoral output maintains a balance with the onsite $\mathrm{CO}_{2}$ emissions of the sector plus the $\mathrm{CO}_{2}$ emissions embodied in intermediate inputs into this sector and those embodied in primary inputs into this sector. $\mathrm{CO}_{2}$ emission intensity of a sector's output, defined as the amount of $\mathrm{CO}_{2}$ that is emitted directly and indirectly to yield per monetary unit of a sector's output, could be then obtained by dividing the $\mathrm{CO}_{2}$ emissions embodied in a sector's output by the total monetary cost of a sector's output. The $\mathrm{CO}_{2}$ emission intensity defined here is applicable to all the products manufactured by the sector, whether they are used as intermediate inputs or as final demand. Meanwhile, products used as household consumption, consumption of non-profit institutions serving households and government consumption are regarded as carbon sinks that ultimately depart from the economic system.

\subsection{Algorithm}

The algorithm for the new embodiment accounting model is established in this section. The world economy is modelled as a $m$-region, $n$-sector network. The balance of carbon flows for sector $i$ in region $s$ is given in Figure 1.

As witnessed, $e_{i}^{s}$ is the onsite $\mathrm{CO}_{2}$ emissions by sector $i$ in region $s ; p_{i}^{s}$ is the primary inputs denoted by the society into sector $i$ in region $s ; q_{j i}^{t s}$ is the 


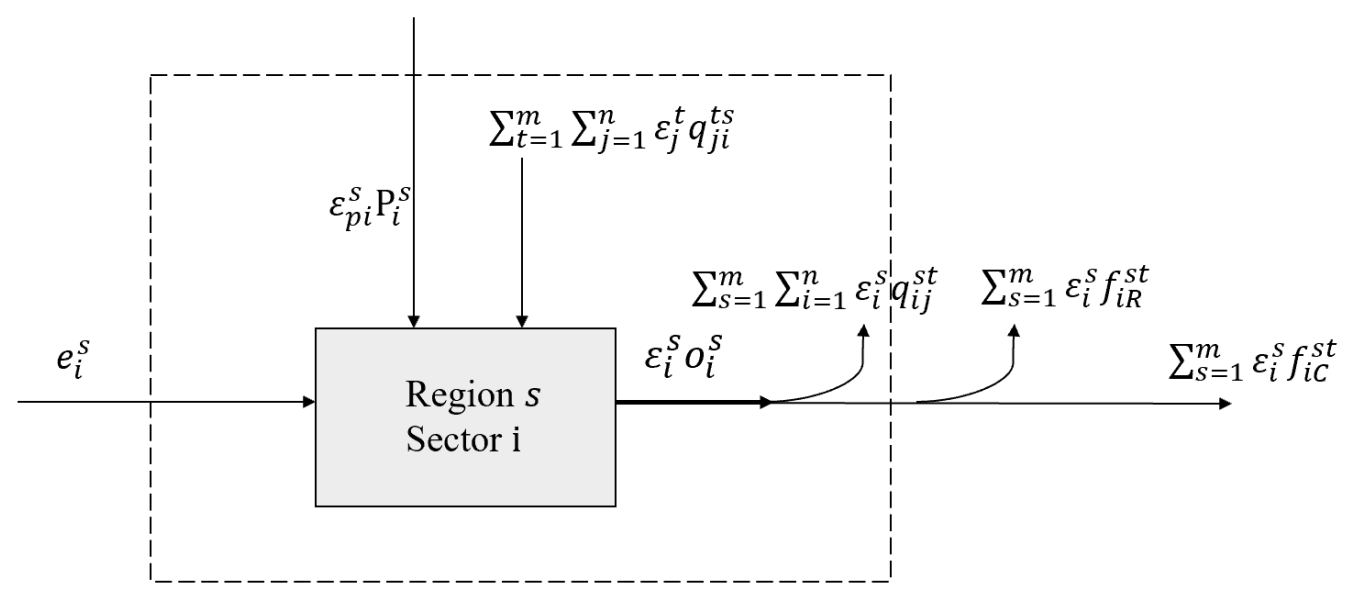

Figure 1: The balance of carbon flows through an industrial sector in the economy

intermediate inputs from sector $j$ in region $t$ into sector $i$ in region $s ; o_{i}^{s}$ is the sectoral output of sector $i$ in region $s ; q_{i j}^{s t}$ denotes the goods or services produced by sector $i$ in region $s$ that are used as intermediate inputs into sector $j$ in region $t ; f_{i C}^{s t}$ represents the goods or services that are produced by sector $i$ in region $s$ and used as household consumption, consumption of non-profit institutions serving households or government consumption in region $t ; f_{i R}^{s t}$ represents the goods or services that are produced by sector $i$ in region $s$ and used as the rest of final demand (inventory change, fixed capital formation, etc.) in region $t ; \varepsilon_{p i}^{s}$ represents the $\mathrm{CO}_{2}$ emission intensity of primary inputs of sector $i$ in region $s ; \varepsilon_{i}^{s}$ represents the $\mathrm{CO}_{2}$ emission intensity of goods or services produced by sector $i$ in region $s ; \varepsilon_{j}^{t}$ represents the $\mathrm{CO}_{2}$ emission intensity of goods or services produced by sector $j$ in region $t$. The balance of carbon flows through sector $i$ in region $s$ could be expressed 
as:

$$
e_{i}^{s}+\varepsilon_{p i}^{s} p_{i}^{s}+\sum_{t=1}^{m} \sum_{j=1}^{n} \varepsilon_{j}^{t} q_{j i}^{t s}=\varepsilon_{i}^{s} o_{i}^{s} .
$$

The matrix notion of Eq. (1) is written as:

$$
E+\varepsilon_{p} \hat{P}+\varepsilon Q=\varepsilon \hat{O},
$$

where $E=\left[e_{i}^{s}\right]_{1 \times m n} ; P=\left[p_{i}^{s}\right]_{1 \times m n} ; \hat{P}$ is the $m n \times m n$ diagonal matrix for $P$; $Q=\left[q_{j i}^{t s}\right]_{m n \times m n} ; \varepsilon=\left[\varepsilon_{i}^{s}\right]_{1 \times m n} ; \varepsilon_{p}=\left[\varepsilon_{p i}^{s}\right]_{1 \times m n} ; O=\left[o_{i}^{s}\right]_{1 \times m n} ; \hat{O}$ is the $m n \times m n$ diagonal matrix for $O$. Besides, the global multi-region input-output table is static, which assumes that the world economy remains stationary. This could be regarded as a most fundamental assumption of the input-output table since it was firstly raised by Leontief (1936). For the steady economy, the economic flows in a given time remain circular. Meanwhile, the embodied carbon emission flows in a given time remain circular and balanced. The external feedback from the society to the economic system is therefore supposed to maintain the balance at any time. The relationship between final demand and primary inputs in the input-output table could be depicted by the socialeconomic matrix (Hanson and Robinson, 1991; Stone, 1973). Whereas, due to the availability and high level of data requirement of the social-economic matrix of the global multi-region input-output account, the primary inputs are not distinguished by sectoral belonging and have an identical $\mathrm{CO}_{2}$ intensity, $\varepsilon_{p a}$. This also conforms to the homogenous assumption that serves a fundamental norm hidden behind the input-output table. Therefore, apart 
264

from Eq. (1), another balance equation may be established as:

$$
\varepsilon_{p c} \sum_{s=1}^{m} \sum_{i=1}^{n} p_{i}^{s}=\sum_{s=1}^{m} \sum_{i=1}^{n} \sum_{t=1}^{m} \varepsilon_{i}^{s} f_{i R}^{s t} .
$$

The matrix notion of Eq. (3) could be written as:

$$
\varepsilon_{p c} P_{\text {sum }}=\varepsilon F_{R}
$$

where $P_{\text {sum }}$ is the aggregated amount of primary inputs; $F_{R}$ represents the $m n \times 1$ column matrix for the rest of final demand. Solving Eq. (2) and Eq. (4) yields:

$$
\varepsilon=E\left(\hat{O}-Q-\frac{1}{P_{\text {sum }}} F_{R} P\right)^{-1}
$$

269 Eq. (5) could also been reduced to a common form as:

$$
\begin{array}{r}
\varepsilon=E \hat{O}^{-1}\left(\hat{O} \hat{O}^{-1}-Q \hat{O}^{-1}-\frac{1}{P_{\text {sum }}} F_{R} P \hat{O}^{-1}\right)^{-1}= \\
e\left(I-A-\frac{1}{P_{\text {sum }}} F_{R} P \hat{O}^{-1}\right)^{-1}=e(I-B)^{-1}
\end{array}
$$

when we define $B=A+\frac{1}{P_{\text {sum }}} F_{R} P \hat{O}^{-1}$, in which $A$ represents the coefficient matrix for intermediate production requirements; $\frac{1}{P_{\text {sum }}} F_{R} P \hat{O}^{-1}$ stands for the feedback associated with capital goods; $e$ is the direct emission multiplier representing the direct emissions corresponding to per unit output of each industry.

With the $\mathrm{CO}_{2}$ emission intensity derived, $\mathrm{CO}_{2}$ emissions embodied in 
each economic flow within the world economy could be obtained. $\mathrm{CO}_{2}$ emissions that sink into region $s$, namely those embodied in the genuine final consumption $(E E C)$ in region $s$, could be established as:

$$
E E C^{s}=\sum_{t=1}^{m} \sum_{j=1}^{n} \varepsilon_{j}^{t} f_{j C}^{t s} .
$$

The extended carbon footprint of region $s$, defined as the total $\mathrm{CO}_{2}$ emissions induced by final consumption of region $s$, can be obtained by summing those embodied in final consumption of region $s$ and the onsite carbon emissions coming from final consumption activities $(\Omega)$ of region $s$, which are expressed as:

$$
E C F^{s}=E E C^{s}+\Omega^{s} .
$$

284 Meanwhile, the territorial-based carbon emissions (TBE) of region $s$ could be established as:

$$
T B E^{s}=\sum_{i=1}^{n} e_{i}^{s}+\Omega^{s} .
$$

${ }_{26} \mathrm{CO}_{2}$ emissions embodied in trade contain those embodied in intermediate trade and those in final trade. $\mathrm{CO}_{2}$ emissions related with intermediate imports and those related with intermediate exports of region $s$ are respectively denoted as:

$$
E I I^{s}=\sum_{t=1(t \neq s)}^{m} \sum_{j=1}^{n} \sum_{i=1}^{n} \varepsilon_{j}^{t} q_{j i}^{t s},
$$


290

and

$$
E I E^{s}=\sum_{t=1(t \neq s)}^{m} \sum_{j=1}^{n} \sum_{i=1}^{n} \varepsilon_{i}^{s} q_{i j}^{s t} .
$$

291 292

and

$$
E T E^{s}=E I E^{s}+E F E^{s} .
$$

${ }_{297}$ Besides, carbon emissions related with intermediate trade balance and

$$
E F I^{s}=\sum_{t=1(t \neq s)}^{m} \sum_{j=1}^{n} \varepsilon_{j}^{t} f_{j}^{t s},
$$

and

$$
E F E^{s}=\sum_{t=1(t \neq s)}^{m} \sum_{i=1}^{n} \varepsilon_{i}^{s} f_{i}^{s t} .
$$

$$
E T I^{s}=E I I^{s}+E F I^{s},
$$

those with final trade balance of Region $s$, respectively denoted by net intermediate imports and net final imports of Region $s$, could be expressed as:

$$
E I T B^{s}=E I I^{s}-E I E^{s},
$$


301

303

304

305

and

$$
E F T B^{s}=E F I^{s}-E F E^{s} .
$$

\subsection{Data sources}

The global multi-region input-output table for the world economy in 2015 comes from Eora database, which offers a time series of global input-output tables from 1990 to 2015 (Lenzen et al., 2012, 2013). Compared to other input-output accounts provided by world input-output database (Timmer et al., 2015), GTAP (Andrew and Peters, 2013), and Exiobase (Tukker et al., 2013), the multi-region input-output table for the world economy in 2015 coming from Eora is by far the most recent statistics available. Within the table, the world is deemed to comprise 189 nations/regions and each nation/region is constituted by 26 economic sectors. Detailed information on the nations/regions and economic industries encapsulated could be referred to SI-A and SI-B in the supporting information. With regard to data from $\mathrm{CO}_{2}$ emissions, this study locates the emphasis specifically on carbon emissions coming from fuel combustion, which are adopted from the environmental satellite account by Eora database that is well matched with the corresponding economic sectors covered in the global input-output account.

\section{Results}

\subsection{The extended carbon footprint of world regions}

Figure 2 presents the top twenty regions in terms of carbon footprint extended. The extended carbon footprint of the United States reaches an 
amount of 7091.79 million tons, ranking the first place. Several other leading regions of carbon footprint extended are mainland China (4586.89 million tons), Japan (1932.29 million tons), India (1949.96 million tons), Russia (1436.04 million tons), Germany (1165.56 million tons), the United Kingdom (1021.70 million tons), France (796.21 million tons), Canada (693.93 million tons) and Italy (690.89 million tons). As seen, the extended carbon footprint of the United States is 1.5 times as much as that of Mainland China; nevertheless, this ratio is accounted as 0.75 in our previous work. The primary reason is that the United States will be apportioned much more $\mathrm{CO}_{2}$ emissions when the social feedback related with capital goods is accounted, since final consumption takes a much larger share of the gross domestic product in the United States (around 80\%) compared to the situation in China (less than $50 \%$ for the past decade). Differing from our previous study where a nation/region's carbon footprint is taken as the emissions embedded in the commodities for final demand, this study takes those commodities for final consumption as the carbon sink; therefore only part of the carbon emissions related with China's final demand could be considered as sinking into the society and those emissions related with capital goods will be circulating within the economy. Moreover, the $\mathrm{CO}_{2}$ emissions embodied in the whole primary inputs of the world economy are calculated as 12871 million tons and are equivalent to $42 \%$ of the emissions embodied in the genuine final consumption, accenting the significant role of capital goods in reallocating global carbon emissions. 
The territorial-based carbon emissions of the regions mentioned above are also depicted in Figure 2, which takes a different shape compared to the picture for the extended carbon footprint of world regions. As seen, mainland China takes the leading position in territorial-based $\mathrm{CO}_{2}$ emissions, with the amount up to 8879.70 million tons. For the United States, while its carbon footprint extended is one and a half times as much as that of mainland China, its territorial-based $\mathrm{CO}_{2}$ emissions are only $68.94 \%$ that of mainland China. For Japan, Germany, the United Kingdom, France and Italy, their territorialbased $\mathrm{CO}_{2}$ emissions are in magnitude $68.02 \%, 79.78 \%, 57.76 \%, 57.58 \%$ and $70.69 \%$ of the extended carbon footprint, respectively. While for India and Russia, this ratio is calculated to be 1.52 and 1.34 .

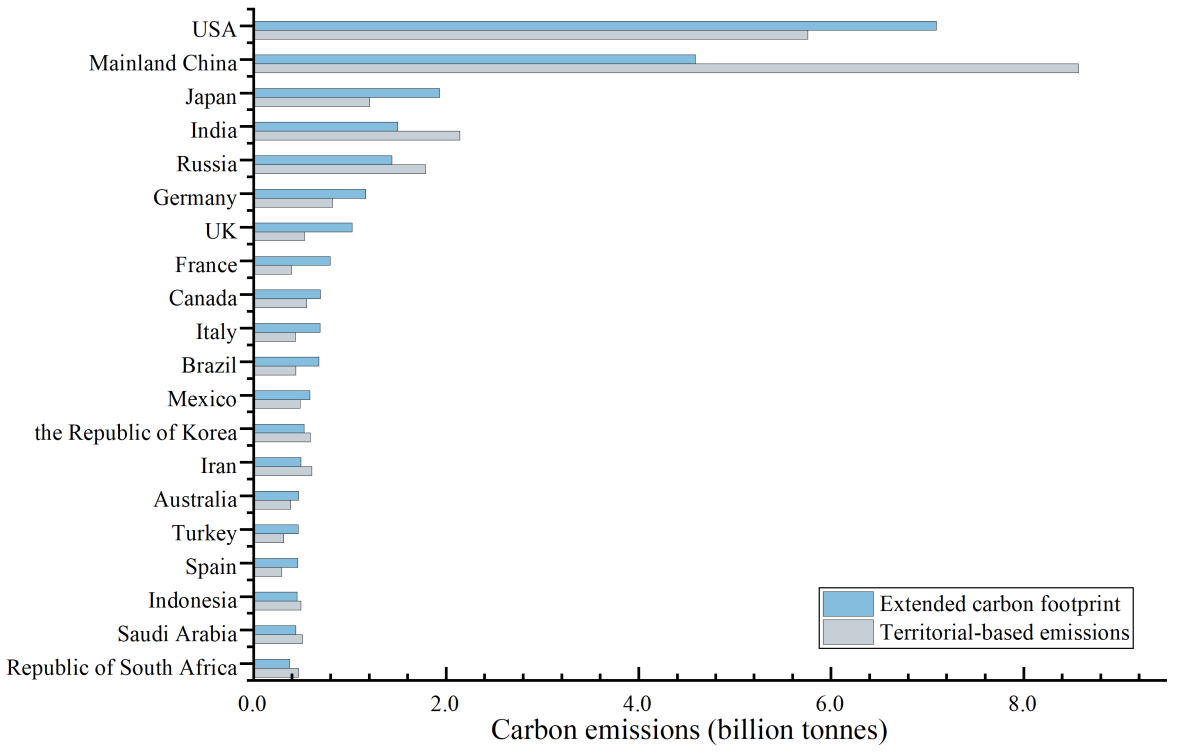

Figure 2: The extended carbon footprint and territorial-based emissions of twenty world regions 


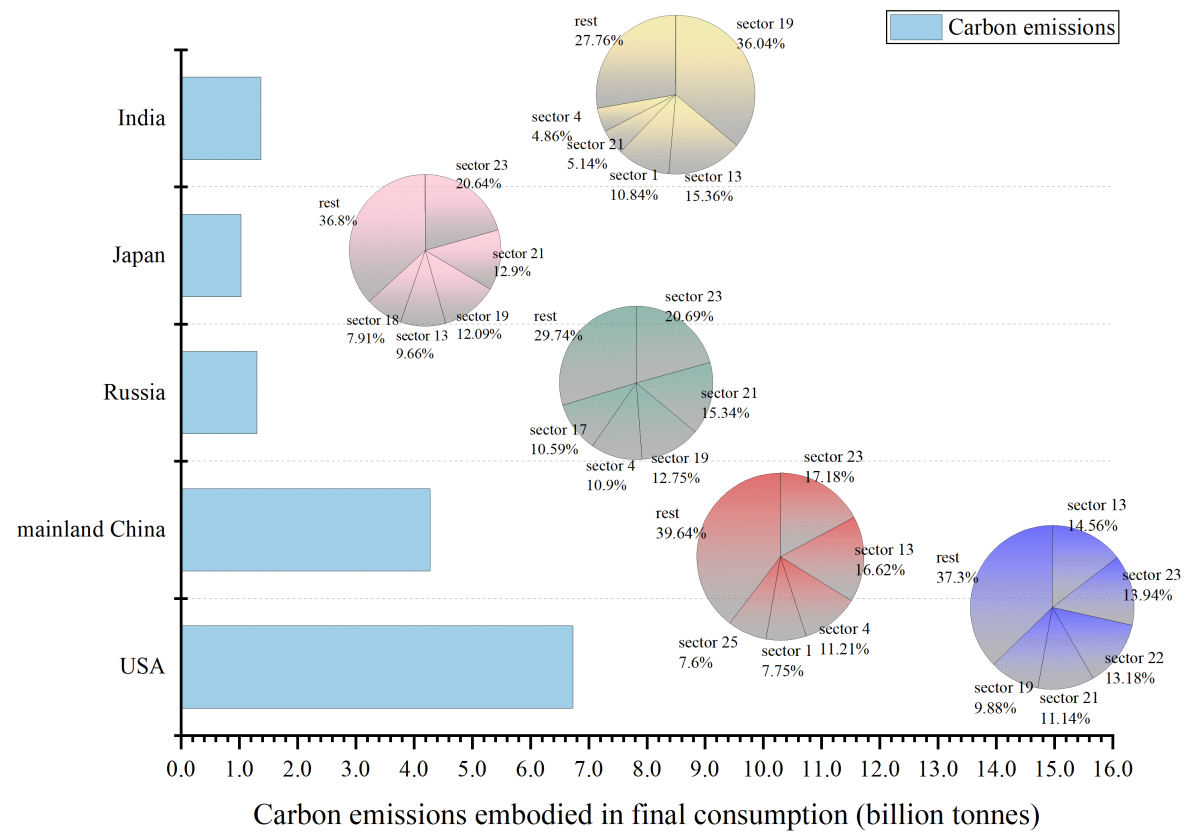

Figure 3: Sectors' contributions to the EEC of the top five regions

Figure 3 presents the sectoral contributions to $\mathrm{CO}_{2}$ emissions embodied in the products used as final consumption (EEC) for the top five regions in terms of carbon footprint extended. As witnessed, Sector 23 (Education, Health and Other Services) is revealed as the largest contributor to the EEC of mainland China, Japan and Russia, which respectively share 17.18\%, $20.64 \%, 20.69 \%$ of their total emissions. This reveals the tremendous requirements of educational and medical services required by the consumers in these three regions, which have induced great quantities of $\mathrm{CO}_{2}$ emissions. For India, the leading sector is Sector 19 (Transport) sharing 36.03\% of its EEC, and Sector 1 (Agriculture) accounts for 10.63\% of India's EEC. As for mainland China, agriculture is accountable for $7.74 \%$ of its EEC. As revealed, 

$50 \%$ of their EEC.

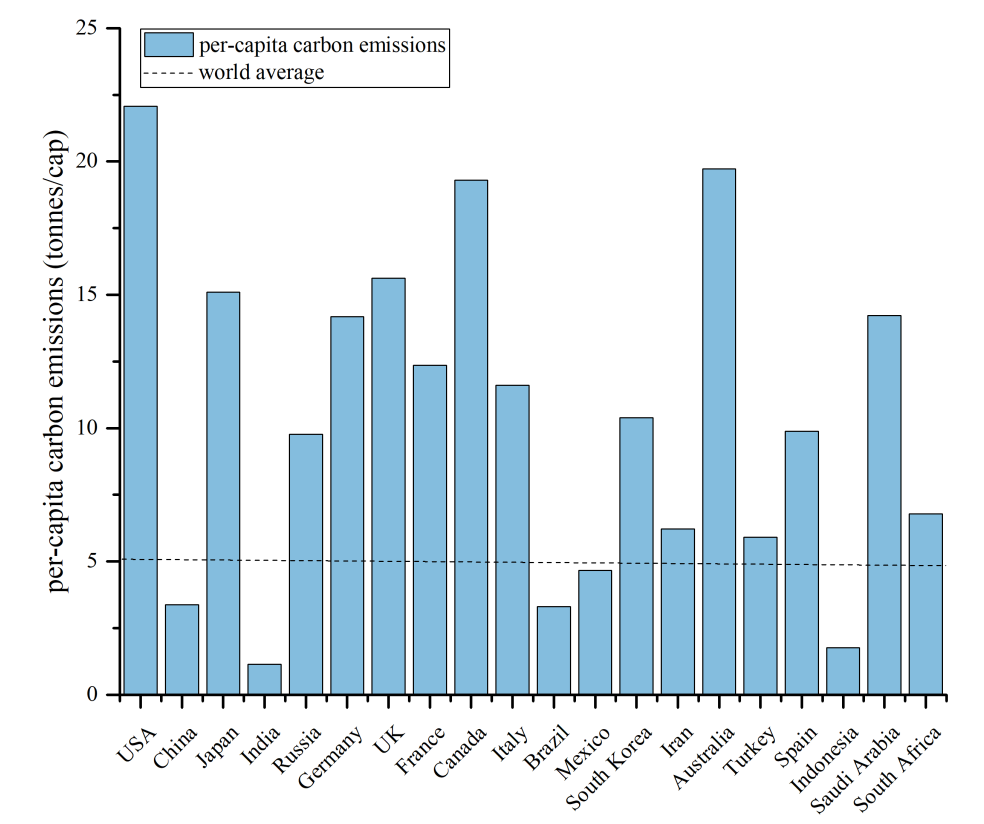

Figure 4: The extended carbon footprint per capita for the twenty regions these two developing nations, which is partly attributed to their long agricultural traditions. While for the United States and Japan, this ratio is less than 1\%. Service sectors, such as Public Administration sector, Financial Intermediation \& Business Activities sector and Transport sector, remain the pillar industries of the two developed nations, altogether dedicating to over

Demonstrated in Figure 4 is the extended carbon footprint per capita for the twenty regions mentioned above. The extended carbon footprint per capita for the United States, Japan, the United Kingdom, Canada, Germany and France are respectively 22.06 tons, 15.10 tons, 15.62 tons, 19.30 tons,

agriculture industry remains an important contributor to $\mathrm{CO}_{2}$ emissions of 
14.18 tons and 12.35 tons, while the world average level is only 6.49 tons. In comparison, the extended carbon footprint per capita for mainland China, India and Brazil are respectively 3.37 tons, 1.14 tons, 3.30 tons, which are in magnitude one half, one fifth, and one half of the world average. As observed, though mainland China takes the leading place in terms of territorial-based carbon emissions and the second place in terms of carbon footprint extended, its extended carbon footprint per capita is only one-sixth of that of the United States, and one-fifth of that of Japan. This tells the wide gap between the development between mainland China and the developed economies.

\section{2. $\mathrm{CO}_{2}$ emissions related with trade}

This section presents the carbon imports and exports associated with commodity trade, with the calculated results presented in SI-C. As reflected in Figure 5, the prominent carbon importers are the United States, mainland China, Germany, Japan, the United Kingdom, France, South Korea, Hong Kong, Italy and Netherlands, with the import volume of $\mathrm{CO}_{2}$ emissions up to 1936.98 million tons, 1108.23 million tons, 1075.80 million tons, 851.34 million tons, 615.85 million tons, 555.88 million tons, 490.09 million tons, 474.56 million tons, 461.76 million tons, and 402.01 million tons. Meanwhile, the United States maintains the first place in both intermediate and final carbon imports. Regarding mainland China, its final carbon imports are only 210.76 million tons, which are only a quarter of those for the United States (815.58 million tons). This has reflected the comparatively lower consumption level 

3.02 and 3.39

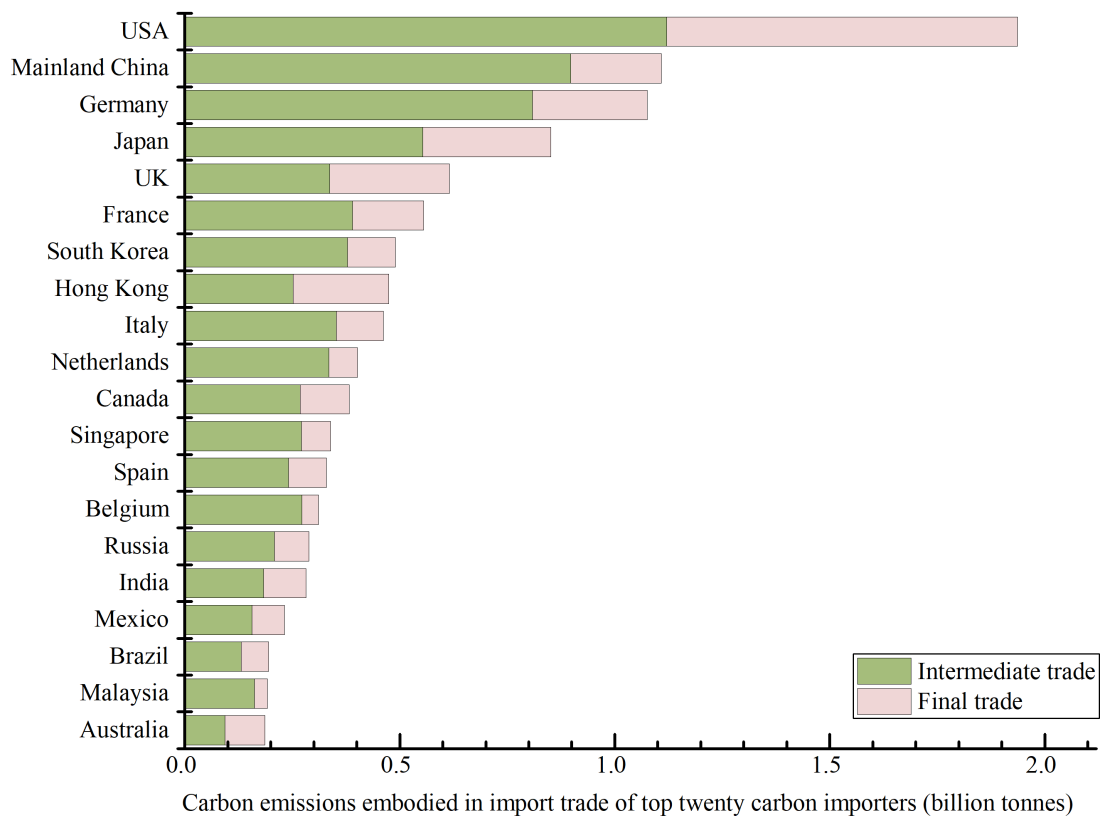

Figure 5: Carbon emissions embodied in the import trade

As for carbon exports associated with commodity trade that are presented 


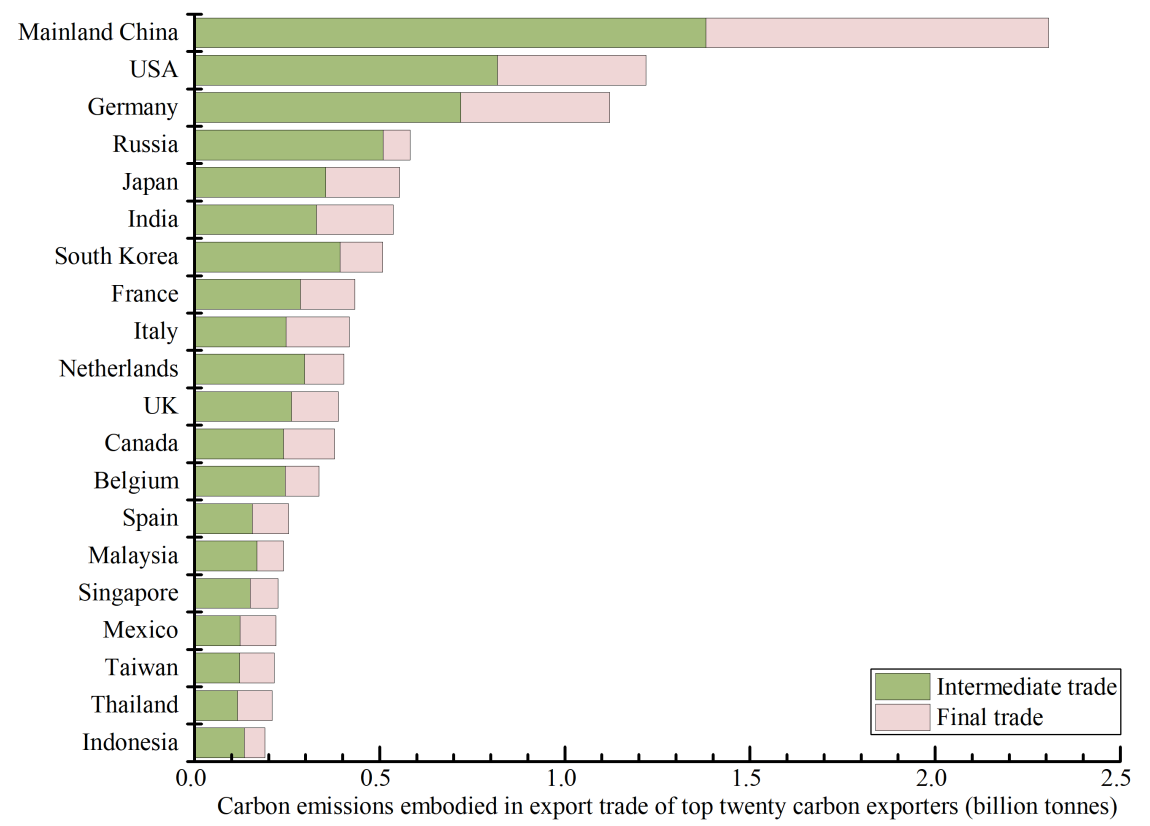

Figure 6: Carbon emissions embodied in the export trade

export volume amounting to 2306.78 million tons. The United States and Germany are the second-tier regions as demonstrated in Figure 6, whose $\mathrm{CO}_{2}$ exports reach 1219.53 million tons and 1121.41 million tons. It is noticed that $\mathrm{CO}_{2}$ exports of the United States and Germany are approximate to each other, which are less than half of those of mainland China. Russia, Japan and India are the third-tier regions, whose $\mathrm{CO}_{2}$ exports are around half of those for the United States and less than a quarter of those for mainland China. The ratios of intermediate $\mathrm{CO}_{2}$ exports to final $\mathrm{CO}_{2}$ exports for mainland China, the United States, Germany, Russia, South Korea, Japan, and India are respectively 1.49, 2.03, 1.78, 6.90, 3.42, 1.71 and 1.59 .

Illustrated in Figure 7 is the carbon trade balance for selected economies. 


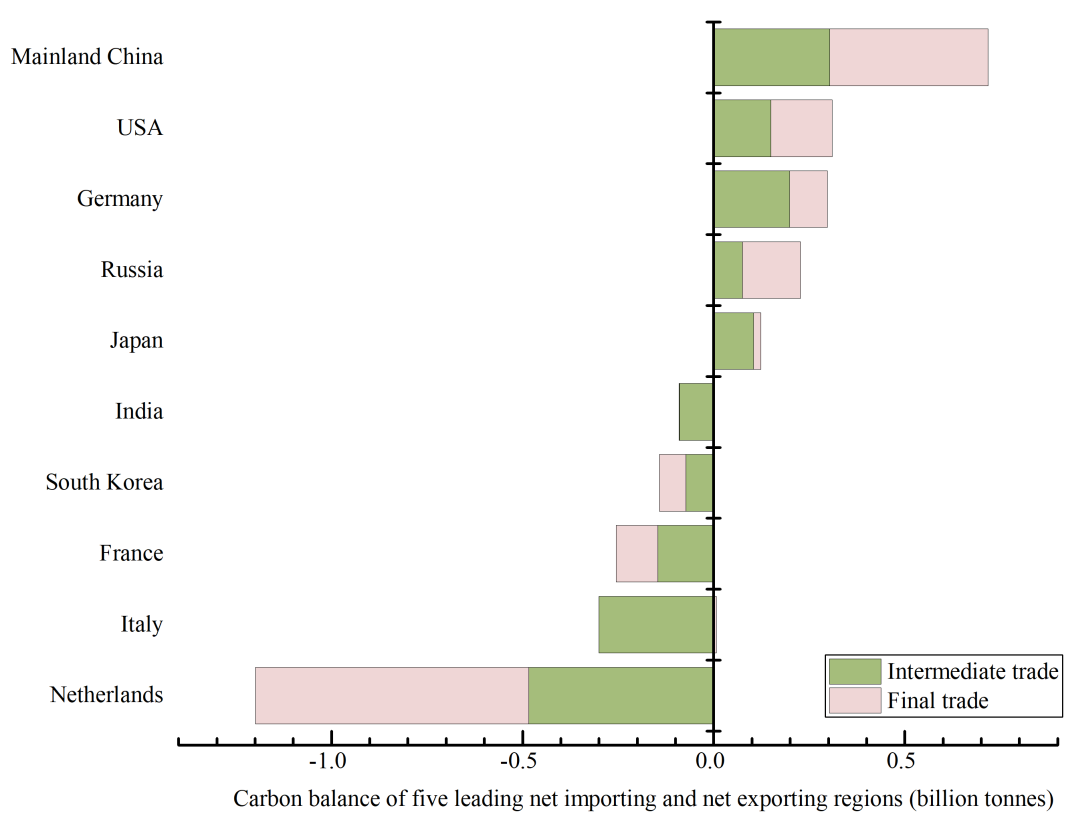

Figure 7: Carbon trade balance of selected regions

Regarding total trade balance, mainland China, Russia, India, Taiwan and South Africa remain the five leading net exporters, whose trade deficits of $\mathrm{CO}_{2}$ emissions respectively reach 1198.54 million tons, 293.63 million tons, 254.93 million tons, 141.58 million tons and 90.13 million tons. In the meanwhile, the five leading net importers of $\mathrm{CO}_{2}$ emissions are the United States, Hong Kong, Japan, the United Kingdom and France, whose trade surpluses of $\mathrm{CO}_{2}$ emissions are respectively 717.44 million tons, 310.35 million tons, 297.73 million tons, 227.05 million tons and 122.99 million tons. The carbon trade surplus of the United States is in magnitude the summation of that of Hong Kong, Japan, the United Kingdom and France. The carbon trade imbalance of mainland China is around one and a half times as much as that of 
the United States, and over four times as much as that of Japan and Russia. In addition, the final trade deficit of $\mathrm{CO}_{2}$ emissions for mainland China is around one and a half times as much as its intermediate trade deficit. This ratio is 0.73 for India and 0.94 for Taiwan. While for Russia, its final trade imbalance of $\mathrm{CO}_{2}$ emissions is in magnitude around $2 \%$ of its intermediate trade imbalance, revealing the highly imbalanced local industrial structure. For the United States, the amount of its carbon surplus in intermediate trade is approximate to its carbon surplus in final trade. Similar circumstances are observed for Hong Kong and the United Kingdom. For Japan, its carbon surplus in intermediate trade doubles its carbon surplus associated with final commodities traded.

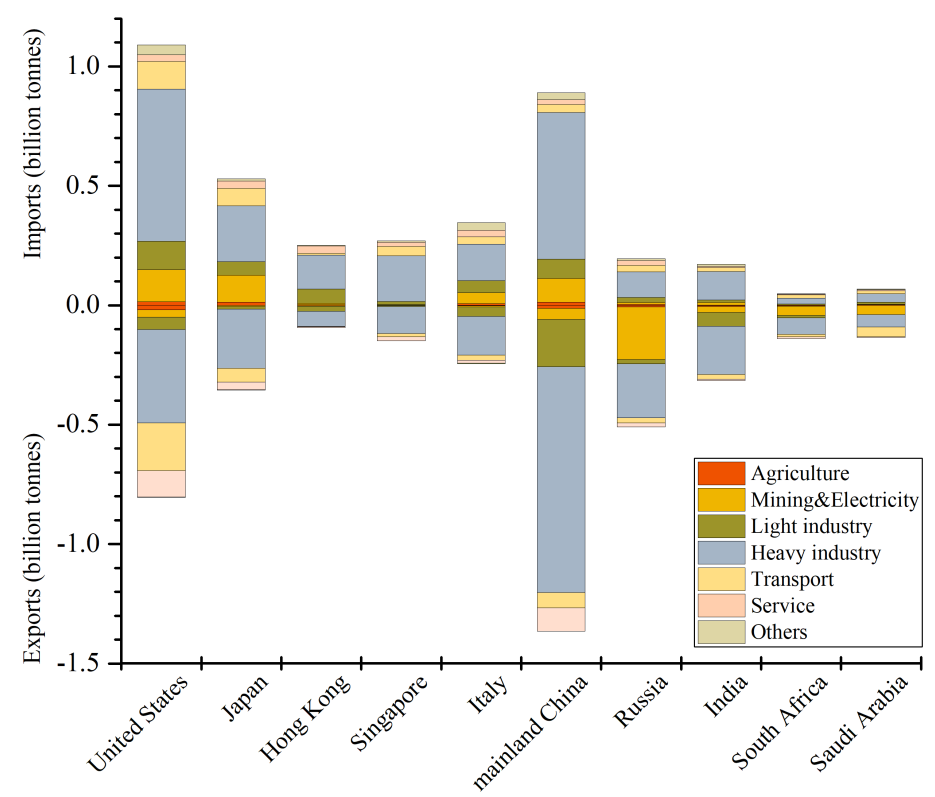

Figure 8: Sectoral shares for the intermediate carbon imports and exports of prominent carbon importing and exporting regions in intermediate commodity trade 
Presented in Figure 8 are the sectoral shares for the intermediate carbon imports and exports of the prominent carbon importers and exporters in intermediate commodity trade. Particulars of the sectoral aggregation are given in the supporting information, SI-B. It is seen that heavy industry is the largest dedicator to both intermediate carbon imports and exports. For the United States, Japan, Hong Kong and mainland China, heavy industry is accountable for $58.54 \%, 44.30 \%, 56.49 \%$ and $68.92 \%$ of their total intermediate carbon imports, respectively. For intermediate carbon exports, heavy industry is accountable for $69.30 \%, 44.22 \%, 63.96 \%, 38.04 \%$ and $48.68 \%$ for those of mainland China, Russia, India, Saudi Arabia and the United States, respectively. It is worth emphasizing that mining \& electricity industry is taking up $43.23 \%$ of Russia's intermediate carbon exports, mainly due to Russia's exceedingly high reliance on oil and natural gas exports. Besides, mining \& electricity industry is accountable for around one-tenth and onefifth of the total intermediate carbon imports of the United States and Japan. Severely deficient of energy resources, Japan has to resort to commodity trade to import large quantities of energy products. Meanwhile, it is worth noticing that transport industry is accountable for around one-tenth and one quarter of the intermediate carbon imports and exports for the United States, respectively.

Illustrated in Figure 9 are the sectoral shares for the final carbon imports and exports of the prominent carbon importing and exporting regions in final commodity trade. For the United States, while heavy industry and light 


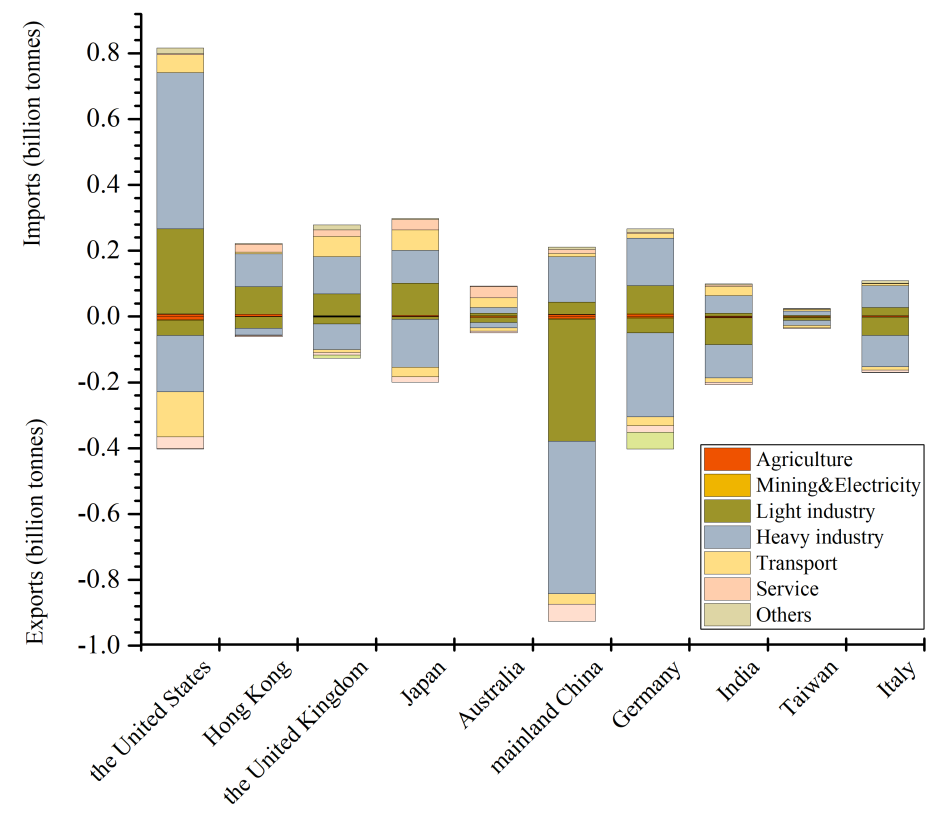

Figure 9: Sectoral shares for the final carbon imports and exports of prominent carbon importing and exporting regions in final commodity trade

industry are the most contributive factors to its final carbon imports (respectively sharing $58.25 \%$ and $31.59 \%$ ), heavy industry and transport industry are the prominent dedicators to the United States' final carbon exports (respectively sharing $42.91 \%$ and $33.82 \%$ ). For Germany as a prominent carbon exporter in final commodity trade, $\mathrm{CO}_{2}$ emissions embedded in its exported heavy industry commodities are around six times as much as those embedded in its exported light industry commodities. Regarding mainland China acting as the largest carbon exporter in final commodity trade, this ratio is around 1.25, implying that mainland China specializes in both heavy industry and light industry commodities in the global market. For Japan, heavy industry, light industry and transport industry are the pillar contributors to its final 
carbon imports, which are sharing $33.38 \%, 32.98 \%$ and $20.73 \%$, respectively. It is also observed that the United Kingdom exhibits an analogical trend to Japan.

\subsection{Carbon transfer between major economies with intertwined trade links}

To formulate the carbon transfer between regions with interconnected trade links, the 189 regions are sorted into 15 aggregated regions, as seen in Figure 10(a) that depicts the links between the 15 regions in intermediate carbon trade. The arc length of each region is a manifestation of its export volume of intermediate commodities, while the chord linking two economies provides the knowledge of their export volume to each other.

Among these fifteen regions China is illustrated as the largest carbon exporter in intermediate commodity trade, with the followers being EU27 and the United States. The main destinations of China's intermediate carbon outflows are EU27, the United States, ASEAN and Japan, which respectively receive 405.32 million tons, 234.76 million tons, 172.00 million tons and 143.40 million tons. China also gains considerable intermediate imports from EU27, Japan, ASEAN and South Korea. Regarding EU27, its intermediate carbon outflows mainly go to USA, China and other Europe \& Eurasia. Besides, EU27 is a leading carbon receiver in intermediate commodity trade. Of EU's total intermediate $\mathrm{CO}_{2}$ imports, $23.64 \%$ of them come from China, 15.58\% coming from Russia, 11.47\% coming from other Europe \& Eurasia, $11.42 \%$ coming from the United States, etc. Regarding USA, it acquires in- 


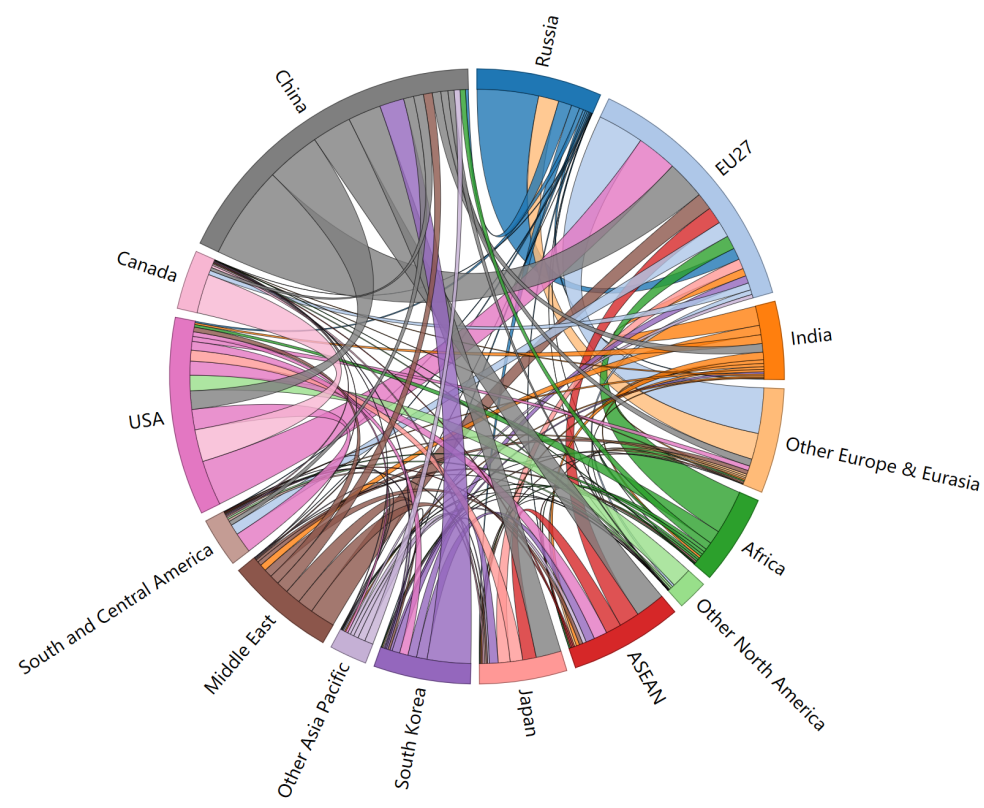

(a)

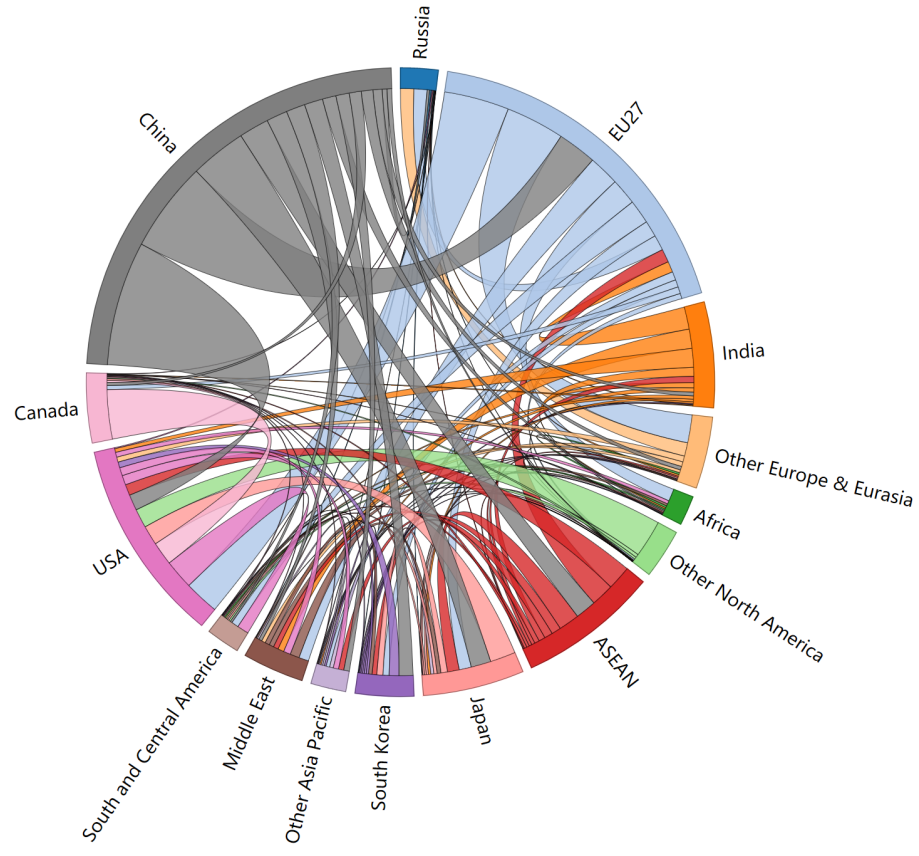

(b)

Figure 10: Carbon links between the 15 regions in (a) intermediate commodity trade and (b) final commodity trade 
termediate $\mathrm{CO}_{2}$ imports from EU27, Canada, and China, which respectively takes up $16.03 \%, 15.68 \%$ and $21.54 \%$ of the total. For Russia, EU27 is the leading recipient of its intermediate $\mathrm{CO}_{2}$ exports, which is accountable for over half of the total. For South Korea, the biggest market for its intermediate $\mathrm{CO}_{2}$ exports is China, accountable for $48.00 \%$.

Presented in Figure 10(b) are the trade links of the 15 economies in final trade of $\mathrm{CO}_{2}$ emissions. The picture is to some degree analogical to that for intermediate $\mathrm{CO}_{2}$ trade. For China acting as the prominent net $\mathrm{CO}_{2}$ exporter in final commodity trade, its $\mathrm{CO}_{2}$ outflows to EU27, the United States, ASEAN and Japan are respectively 190.30 million tons, 261.56 million tons, 63.16 million tons and 118.09 million tons. For Japan, while it absorbs abundant final $\mathrm{CO}_{2}$ imports, it delivers an extensive amount of $\mathrm{CO}_{2}$ emissions to USA, EU27 and South Korea. Canada is revealed to be a notable carbon exporter in final commodity trade, four thirds of whose exported $\mathrm{CO}_{2}$ emissions in final trade enter the United States.

Figure $11(\mathrm{a})$ presents the prominent $\mathrm{CO}_{2}$ flows related with net intermediate trade on the world map. China is the largest net $\mathrm{CO}_{2}$ exporter, while EU27 is the prominent net $\mathrm{CO}_{2}$ importer in intermediate commodity trade. The most notable net intermediate flow of $\mathrm{CO}_{2}$ emissions is demonstrated to be that from China to EU27 amounting to 237.39 million tons, followed by that from Russia to EU27 amounting to 215.86 million tons, and that from China to USA amounting to 155.01 million tons. Meanwhile, it is reflected that China has a $\mathrm{CO}_{2}$ deficit in intermediate commodity trade with almost 
all its trading partners except for some regions such as South Korea and Russia. China absorbs a net intermediate inflow of 82.41 million tons of $\mathrm{CO}_{2}$ emissions from South Korea and 45.43 million tons from Russia. Regarding EU27, apart from China and Russia being its net importing markets of $\mathrm{CO}_{2}$ emissions, Africa and India are revealed to obtain a carbon deficit of 132.32 million tons and 50.06 million tons of $\mathrm{CO}_{2}$ emissions in intermediate commodity trade with EU27. Regarding South Korea, the most remarkable net intermediate inflow of $\mathrm{CO}_{2}$ emissions into this region is that from Middle East while the prominent net intermediate outflow of $\mathrm{CO}_{2}$ emissions from South Korea goes to China. For Japan, it appears to acquire a $\mathrm{CO}_{2}$ surplus with all its trade partners.

Figure 11(b) presents the prominent $\mathrm{CO}_{2}$ flows related with net final trade on the world map. The largest net $\mathrm{CO}_{2}$ flow in final commodity trade is that from China to USA reaching 228.30 million tons, followed by that from China to EU27 reaching 108.41 million tons and that from China to Japan reaching 76.39 million tons. As seen, China appears to serve the world market in final commodity trade, which is reflected to acquire a carbon deficit with all of its trade companions. For USA, it is reflected to get a prominent carbon surplus in final commodity trade. A net $\mathrm{CO}_{2}$ emission inflow of 63.65 million in final trade occurs from EU27 to the United States, suggesting the environmental welfare received by USA from EU27. Besides, USA neighbors, including Canada and other North America, contribute remarkably to the United States' carbon surplus in final commodity trade, whose net $\mathrm{CO}_{2}$ ex- 


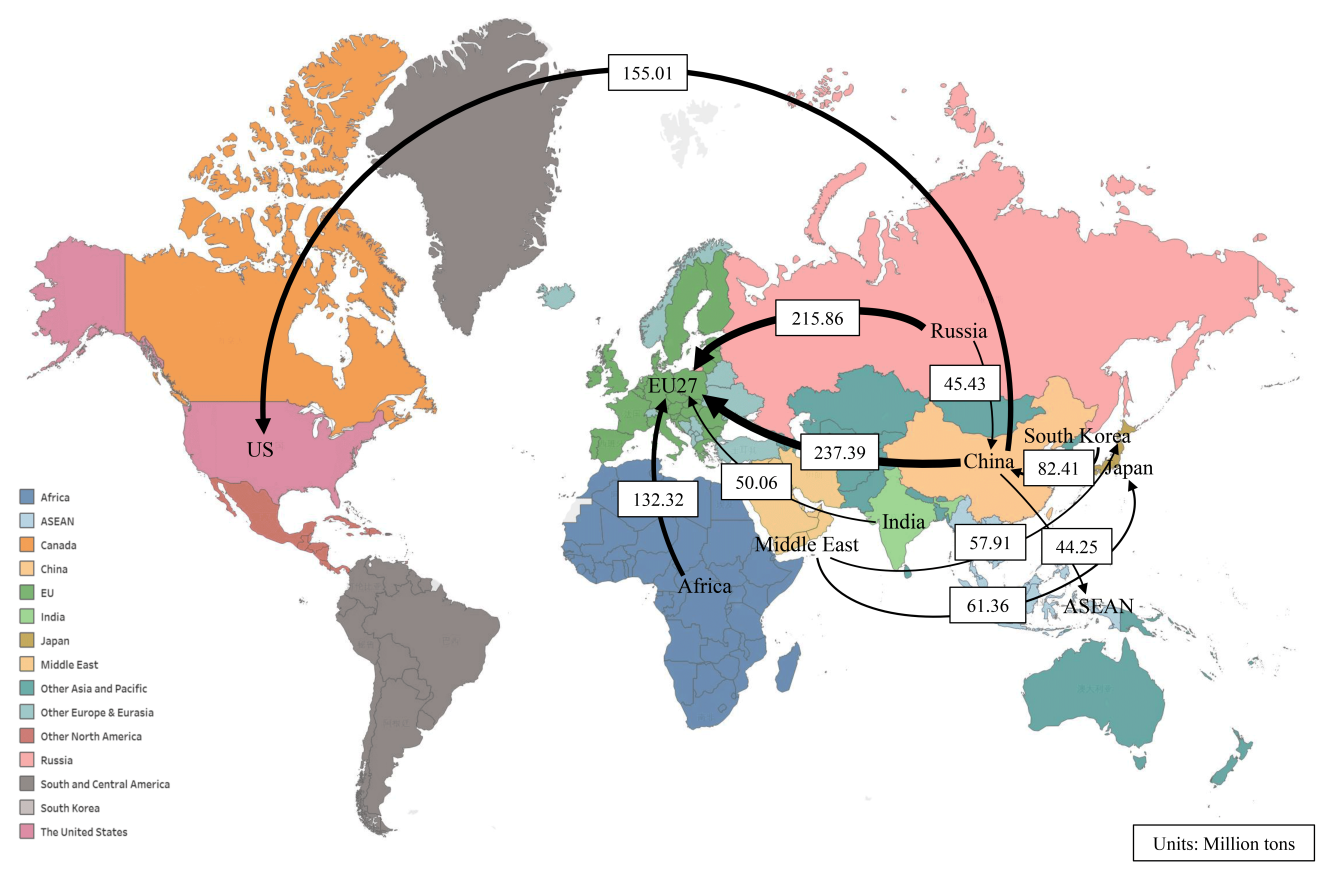

(a)

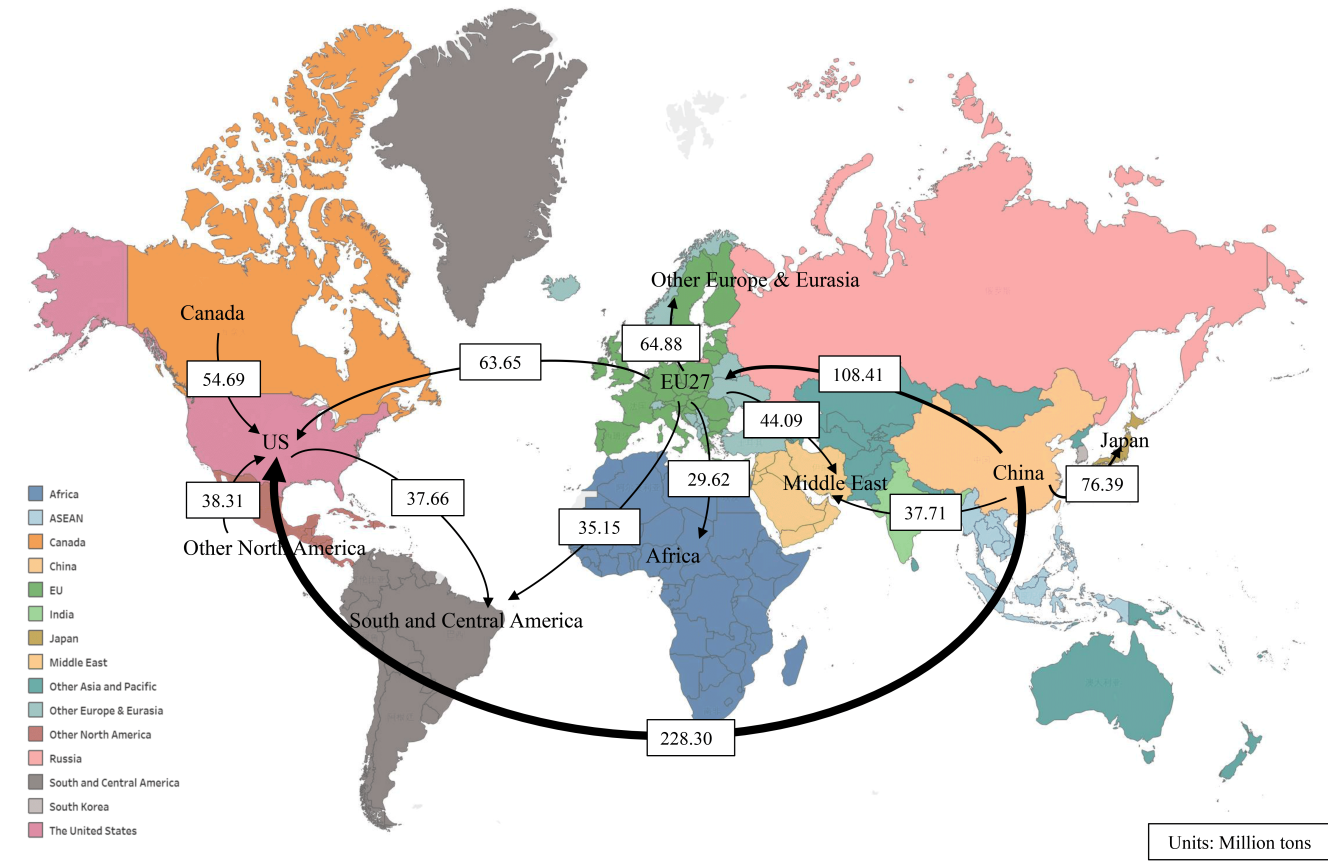

(b)

Figure 11: Prominent $\mathrm{CO}_{2}$ flows related with (a) net intermediate commodity trade and (b) net final commodity trade 
ports in final trade to the United States reach 54.69 million tons and 38.31 million tons, respectively. Regarding EU27, it is proved to be a net $\mathrm{CO}_{2}$ exporter in final commodity trade. The major destinations of its net final exports of $\mathrm{CO}_{2}$ emissions are USA, other Europe \& Eurasia, South \& Central America, Middle East and Africa.

\section{Discussion}

\subsection{Trade patterns}

The trade patterns for major economies are analyzed on the economic and also the biophysical dimensions. Presented in Figure 12 are the monetary and $\mathrm{CO}_{2}$ emission trade balances for some selected economies. The quantum of trade for an economy is reflected by the size of the related sphere. For mainland China, it is reflected to get an economic surplus of 369.92 billion dollars in commodity trade and a $\mathrm{CO}_{2}$ emission deficit of 1198.54 million tons. Germany is also reflected to be in the fourth quadrant in the rectangle coordinate. While Germany's economic surplus in commodity trade is larger than that of mainland China, its carbon emission deficit is only 45.61 million tons, which is only around one-twenty-sixth of that for mainland China. This has revealed the different characters played by these two prominent exporters in the international market. Mainland China is on the downstream low-value chain while Germany is on the upstream high-value chain of global trade market. Therefore, mainland China manufactures an extensive number of commodities with low value at the cost of intensive fuel consumption and 
carbon emissions, while Germany obtains a remarkable amount of monetary revenues by delivering the commodities with high value abroad and in the meanwhile offsets its carbon emission trade deficit by importing a great many commodities with low value from emerging markets. In this way, Germany realizes the maximization of economic profits at the low cost of environmental degradation.

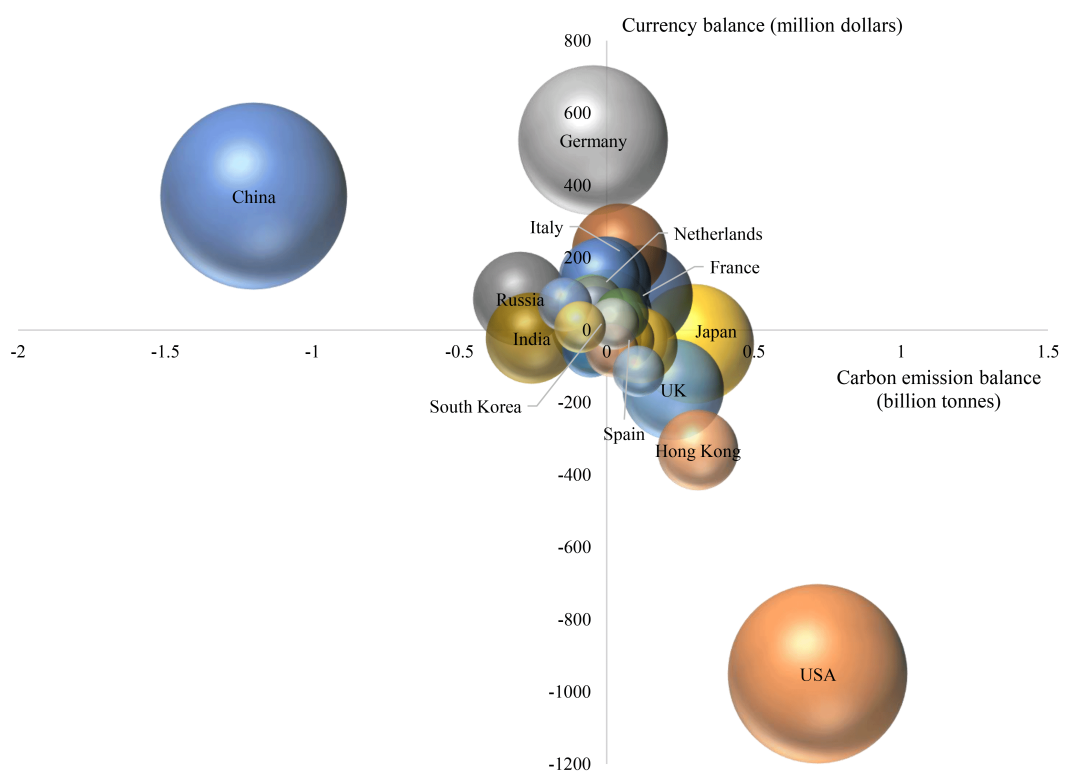

Figure 12: Monetary and carbon trade balances for major economies

574 For the developed economies including the United States, Hong Kong and the United Kingdom, they get an economic deficit and a carbon emission surplus in international commodity trade. These economies get a large quantity of products from abroad for the consumption of domestic citizens, thus getting an economic deficit in trade but absorbing the environment welfare by shifting the $\mathrm{CO}_{2}$ emissions to other nations. For Japan, France, Italy and 
Netherland, they are recipients of net currency and $\mathrm{CO}_{2}$ emission inflows. These economies are prominent importers and also exporters in the global market. For instance, Japan owns a reputation for the electronic products and automobiles; France is famous for their renowned commodities including automobiles (Renault, Peugeot, Citroen, etc.), high-end clothing and makeup (Pierre Cardin, Chanel, LV, DIOR, etc.); Netherland owns a reputation for the high-end agricultural products. It is due to this that they acquire an economic surplus in global trading market. Besides, they import plenty of intermediate and consumer products from mainland China and India, consequently transferring the environmental burden to the developing economies via commodity trade. For India locating in the third quadrant of the rectangle coordinate, it gets an economic deficit and also a carbon emission deficit in commodity trade.

Presented in Figure 13 are the trade patterns for selected economies in intermediate carbon trade and final carbon trade. The United States, the United Kingdom, Hong Kong, Japan and France feature a $\mathrm{CO}_{2}$ emission surplus in intermediate and final commodity trade. Regarding Germany, Netherland, Canada and Italy, they are reflected to get a $\mathrm{CO}_{2}$ emission surplus in intermediate commodity trade and a $\mathrm{CO}_{2}$ emission deficit in final commodity trade. They combine their comparative advantages to acquire the economic benefits, by utilizing the global supply chain to provide them the materials and other intermediate products at low price for further processing in domestic industries, and delivering a large quantity of final commodities 
603

to foreign regions.

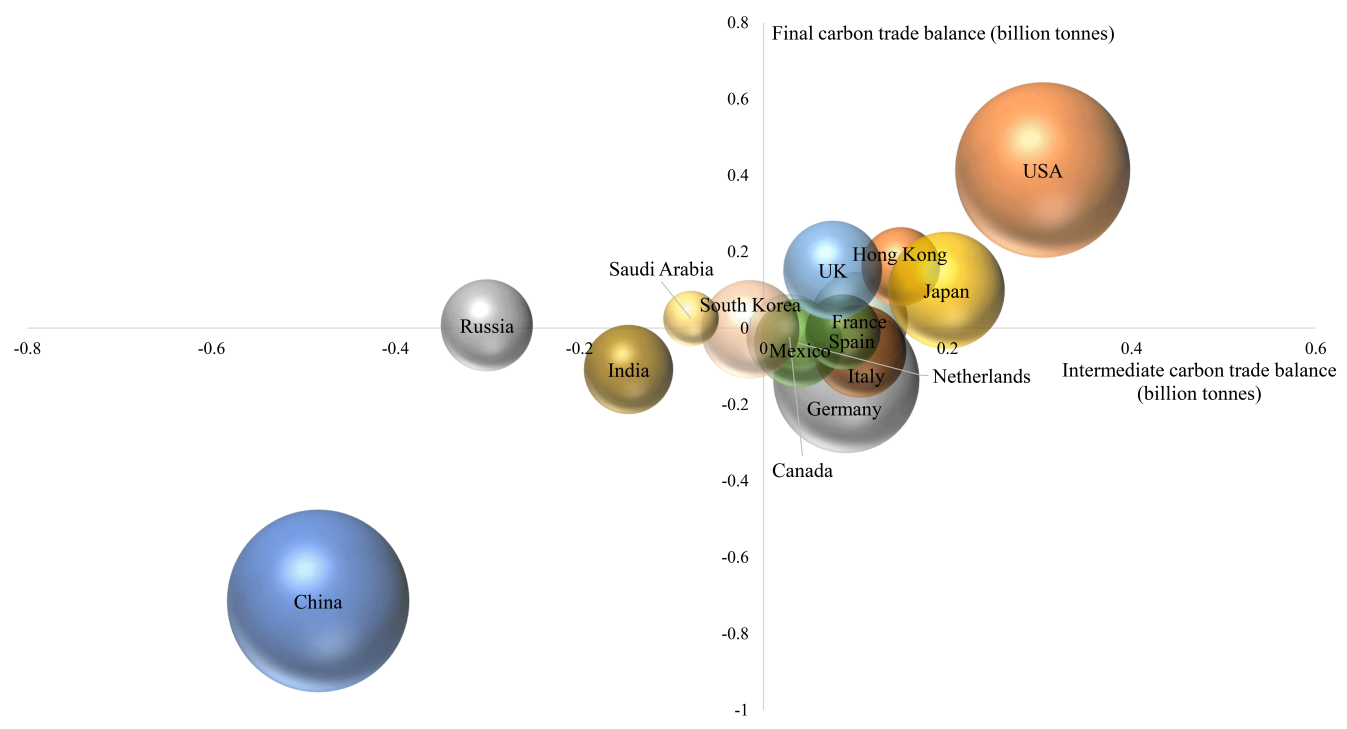

Figure 13: Carbon balances for major economies in intermediate and final commodity trades

Regarding mainland China and India, they get a $\mathrm{CO}_{2}$ emission deficit in intermediate and final commodity trades. The $\mathrm{CO}_{2}$ emission deficits for mainland China in intermediate and final commodity trades are respectively 483.92 million tons and 714.61 million tons. As seen, mainland China's final carbon trade imbalance outpaces its intermediate carbon trade imbalance by around half. Therefore, on one hand, mainland China delivers a large quantity of intermediate commodities to developed economies for further processing, thus getting a remarkable $\mathrm{CO}_{2}$ emission deficit in intermediate commodity trade. On other hand, mainland China is also the prominent supplier of final commodities with low value. In the short term, mainland China may experience an economic boom, as proved by the unprecedented 
economic growth in the past thirty years. While at the same time, this is not a sustainable way. The increasingly severe environmental and climate problems, such as water scarcity, soaring $\mathrm{CO}_{2}$ emissions and haze, are harassing the domestic citizens as well as the government. In recent years, the central government of China came to attach importance to this problem and adjust the economic structure from a carbon-intensive, and low-value manufacturing-oriented economy to a green and service-oriented economy. It is raised in the national report that mainland China is going to deepen the structural reforms from the supply side and consolidate the development of advanced manufacturing and modern service industries, thus making the domestic industries climb from the downstream chain with low value to upstream supply chain with high value in the global market (Xi, 2017).

Regarding Russia and Saudi Arabia, they get a $\mathrm{CO}_{2}$ emission deficit in intermediate commodity trade and a $\mathrm{CO}_{2}$ emission surplus in final trade. The intermediate carbon trade imbalance is respectively over one hundred times and around five times as much as its final carbon trade imbalance for Russia and Saudi Arabia, respectively. Energy products such as oil and natural gas, dominate the export trade of these two nations. Especially, Russia relies on exporting energy products in exchange of the consumer goods needed by domestic citizens, thus resulting in the tremendous $\mathrm{CO}_{2}$ emission deficit in intermediate commodity trade. The unbalanced economic structure may be a hidden problem for Russia. The downfall of oil price could be a catastrophe for Russia's economy. This has to some extent implied the unsustainable 
trend of Russia's trade patterns.

\subsection{Geographic and sectoral profiles for carbon trade of distinct economies}

Geographic and sectoral profiles for the $\mathrm{CO}_{2}$ emission imports and exports of two distinct economies (USA and China) are presented here. Figure 14(a) and Figure 14(b) respectively offer the information for USA's $\mathrm{CO}_{2}$ emission imports and exports. For USA, Asia \& Pacific is the largest source region for its $\mathrm{CO}_{2}$ emission imports. Asia Pacific is accountable for around half of $\mathrm{CO}_{2}$ emissions embodied in the United States' imported heavy industry products, half of those in the United States' imported light industry products, and around $40 \%$ of those in the United States' imported transport services. For North America as another crucial contributor to the United States' imports, heavy industry commodities are accountable for around $60 \%$ of North America's $\mathrm{CO}_{2}$ emission exports to the United States. Regarding the $\mathrm{CO}_{2}$ emissions embodied in the imported heavy industry products of the United States, around $40 \%$ of them go to final demand in the United States; $36.68 \%$ of them are delivered to heavy industry in the United States; $14.43 \%$ of them flow to service industry in the United States, etc. With regard to the carbon imports from light industry abroad, $68.45 \%$ of them are delivered to domestic final demand; $16.07 \%$ of them are delivered to domestic light industry, etc. As for USA's $\mathrm{CO}_{2}$ emission exports, heavy industry, transport industry and service industry are the largest three carriages driving its exports. For carbon exports by the heavy industry of the United States, around 30\% 


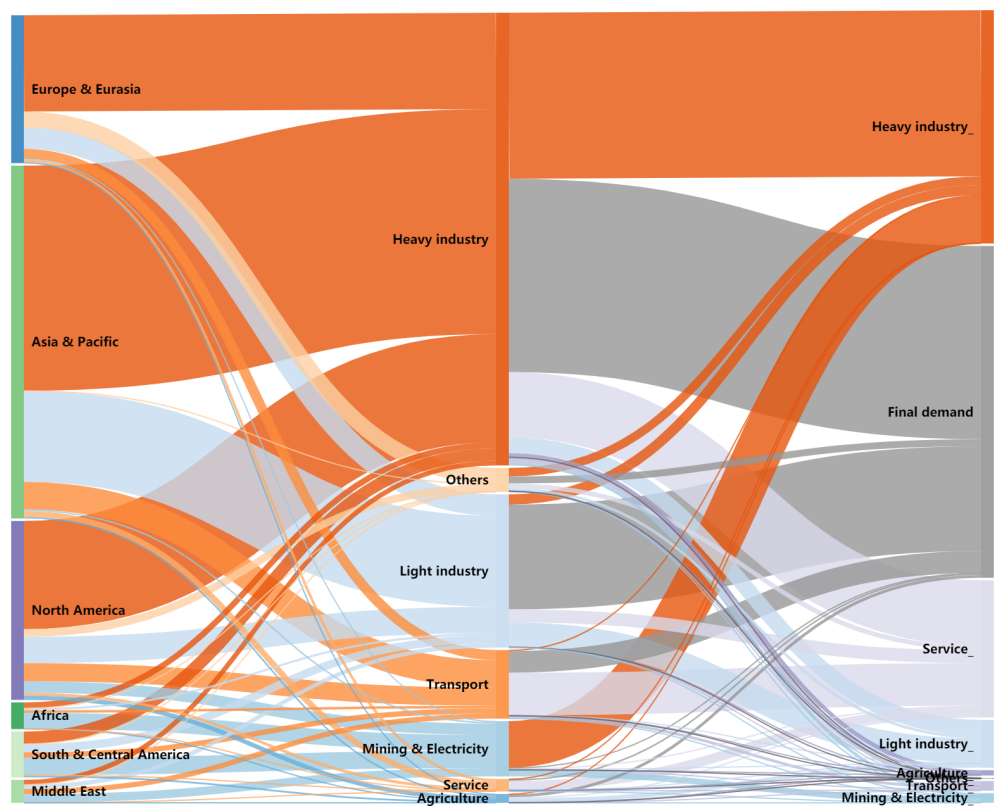

(a)

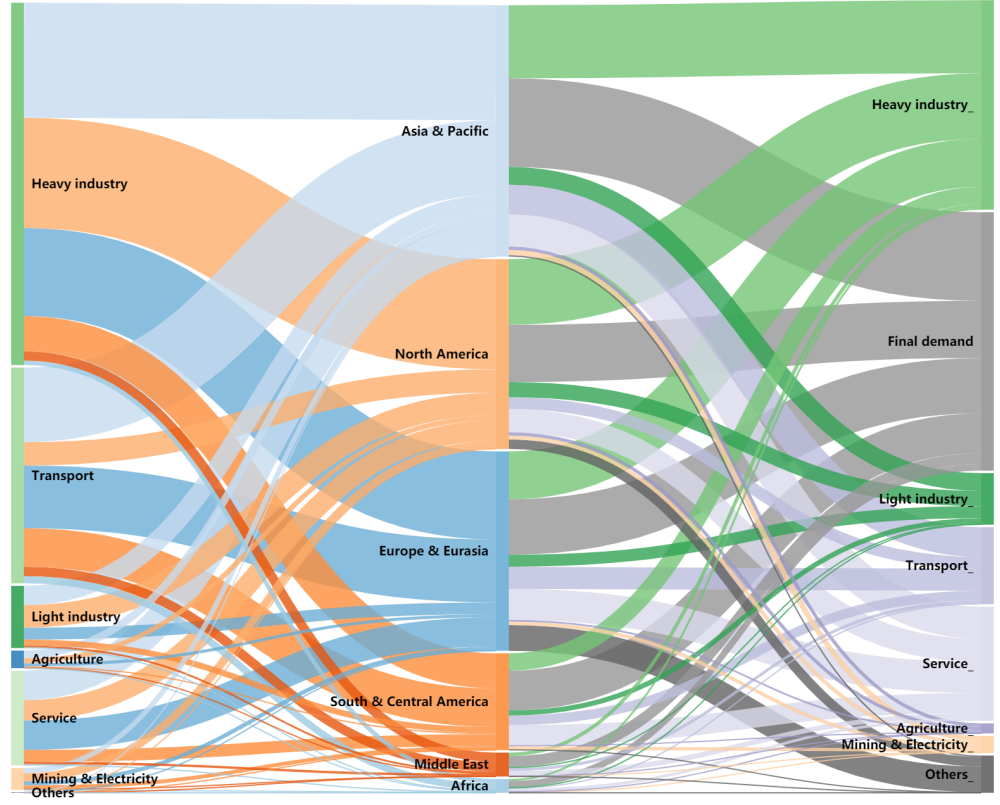

(b)

Figure 14: Geographic and sectoral profiles for (a) $\mathrm{CO}_{2}$ emission imports and (b) exports of USA 
of them are taken in by North America, 30\% received by Asia Pacific, one quarter of them received by Europe \& Eurasia, and one-tenth received by South \& Central America. With regard to the carbon exports by transport industry of the United States, the two major recipients are Asia Pacific, and Europe \& Eurasia, manifesting the huge demand in these regions for transport services provided by the United States. Meanwhile, for the $\mathrm{CO}_{2}$ emission exports from the United States to Asia \& Pacific, around one third of them are delivered to final demand. This ratio turns out to be around one quarter for those from the United States to Europe \& Eurasia, around one third for those from the United States to Asia \& Pacific as well as North America, and over $40 \%$ for those from the United States to Middle East as well as those from the United States to Africa.

Illustrated in Figure 15(a) and Figure 15(b) is the information for $\mathrm{CO}_{2}$ emission imports and exports of mainland China. As seen in Figure 15(a), Asia \& Pacific is responsible for around half of mainland China's total $\mathrm{CO}_{2}$ emission imports. Meanwhile, heavy industry in foreign regions accounts for $70 \%$ of mainland China's total $\mathrm{CO}_{2}$ emission imports. Asia Pacific dedicates $57.56 \%$ of the total imports from foreign heavy industry into mainland China, followed by Europe \& Eurasia dedicating $29.31 \%$, etc. Meanwhile, $64.29 \%$ of mainland China's $\mathrm{CO}_{2}$ emission imports from foreign heavy industry enter domestic heavy industry, while only $18.36 \%$ of them enter domestic final demand. As seen in Figure 15(b), the three major recipients of carbon exports by mainland China's heavy industry are Europe \& Eurasia, Asia \& Pacific, 


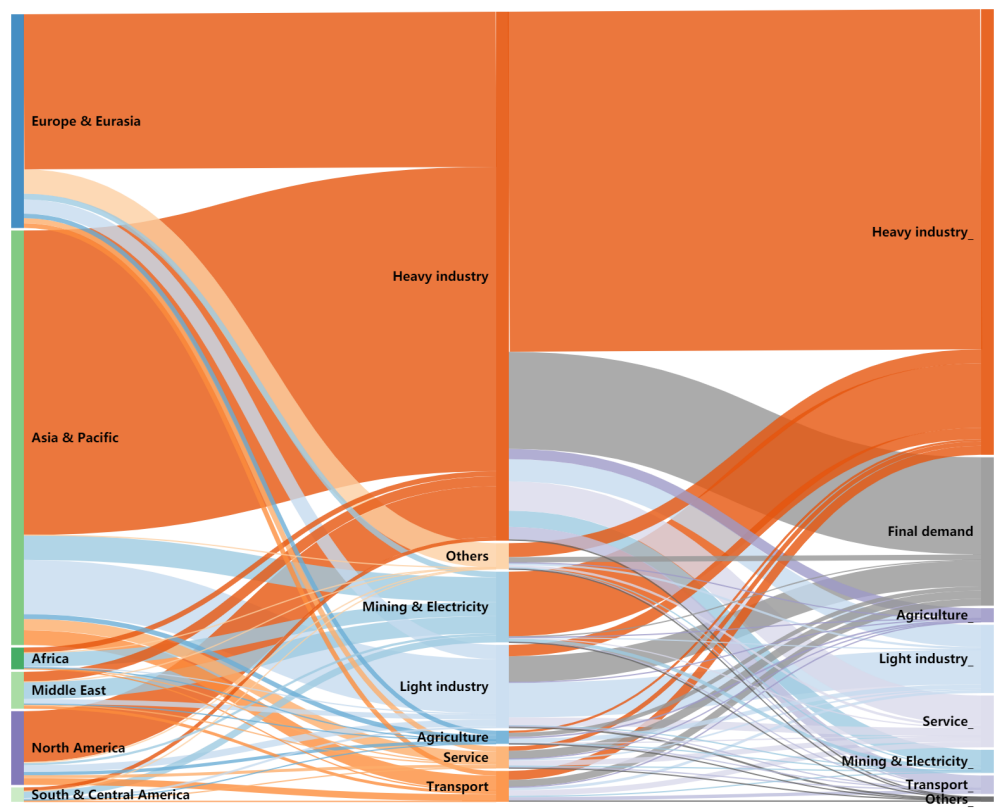

(a)

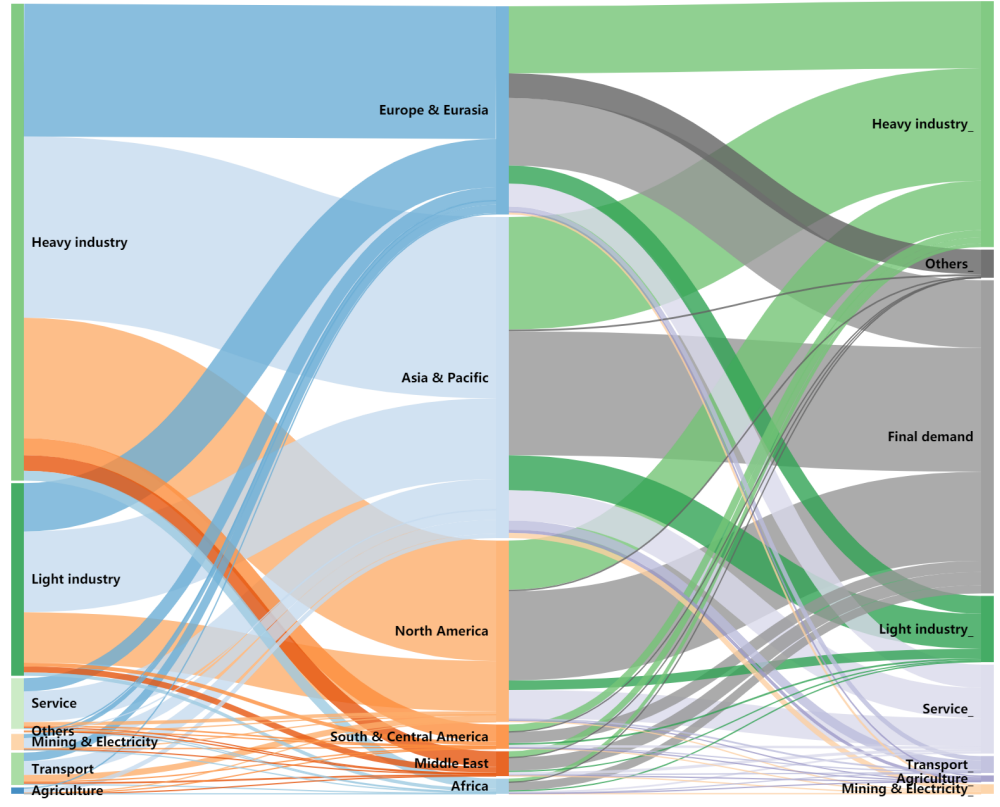

(b)

Figure 15: Geographic and sectoral profiles for (a) $\mathrm{CO}_{2}$ emission imports and (b) exports of mainland China 
and North America. For the carbon exports from mainland China to Europe \& Eurasia, around one-third of them enter mainland China's final demand. This ratio is revealed as $38.59 \%$ for those from mainland China to Asia \& Pacific, $49.12 \%$ for those from mainland China to North America, 46.51\% for those from mainland China to South \& Central America, 54.21\% for those from mainland China to Africa, and $53.14 \%$ for those from mainland China to Middle East.

\section{Conclusions}

Measuring and analysing the carbon emissions is a necessary step in the way of dealing with climate change. For a comprehensive understanding of the extended carbon footprint of world regions as well as the $\mathrm{CO}_{2}$ emission transfer in global commodity trade, this study adopts a systems multi-region input-output approach with primary inputs into consideration and analyses the $\mathrm{CO}_{2}$ emissions for the world in 2015 on a collective nation (region) level by utilizing the latest statistics.

The extended carbon footprint of the United States is revealed as one and a half times as much as that of China, while this ratio is accounted as three quarters in our previous work, which is due to that final consumption takes a much larger share of the gross domestic product in the United States compared to the situation in China. $\mathrm{CO}_{2}$ emissions embodied in the whole primary inputs of the world economy are calculated to be equivalent to $42 \%$ of the emissions embodied in the genuine final consumption, high- 
lighting the key role of capital goods in reallocating global carbon emissions. Moreover, global commodity trade causes the displacement of an extensive amount of carbon emissions around the world. For the interregional transfer of $\mathrm{CO}_{2}$ emissions, around $70 \%$ of the emissions are related with intermediate commodity trades, and only around $30 \%$ of them are related with final commodity trades.

Results from this study indicate that regions tend to have different trade patterns in intermediate and final commodity trades. The United States, the United Kingdom, Hong Kong, Japan and France have a $\mathrm{CO}_{2}$ emission surplus in intermediate and final commodity trades, while Russia and Saudi Arabia are characterized by a $\mathrm{CO}_{2}$ emission deficit in intermediate commodity trade but a $\mathrm{CO}_{2}$ emission surplus in final commodity trade, as energy products dominate the export of these two countries. Germany, Netherland, Canada and Italy are characterized by a $\mathrm{CO}_{2}$ emission surplus in intermediate commodity trade and a $\mathrm{CO}_{2}$ emission deficit in final commodity trade, indicating that these countries make well use of their status of being on the high end of the global supply chain, importing low value-added materials from around the world for further processing and then exporting high value-added final commodities, and in turn capturing immense economical and environmental benefits. For mainland China and India, they are characterized by a $\mathrm{CO}_{2}$ emission deficit in both intermediate and final commodity trade. These countries, especially mainland China, deliver a large quantity of intermediate commodities to developed countries for further processing, and at the same 
time export lots of final commodities to the world market, indicating that these countries serve as mills and plants of the world. For eager emerging developing economies, trade in intermediates and low value-added final goods is often a first step into the world market, and a plank for these emerging economies to integrate into the world economy. However, such growth pattern is bound to induce major environmental problems, far beyond soaring $\mathrm{CO}_{2}$ emissions.

The interaction between international trade and climate change has major implications for countries around the world. Identifying the trading structures of $\mathrm{CO}_{2}$ emissions embodied in international trade is a further step towards more inclusive information regarding the issue of the establishment of global warming regimes, and may help us seek more informed policy choices and trade measures in global trade negotiations.

\section{Acknowledgments}

This research is supported by the National Natural Science Foundation of China (Grant No. 71904003).

\section{Additional Information}

Declarations of Interest: None 


\section{References}

Andrew, R.M., Peters, G.P., 2013. A multi-region input-output table based on the global trade analysis project database (GTAP-MRIO). Economic Systems Research 25, 99-121. doi:10.1080/09535314.2012.761953.

Apple, 2018. Supplier List. Technical Report. Apple Supplier Responsibility.

Bullard, C.W., Herendeen, R.A., 1975a. The energy cost of goods and services. Energy Policy 3, 268-278.

Bullard, C.W., Herendeen, R.A., 1975b. Energy impact of consumption decisions. Proceedings of the IEEE 63, 484-493.

Cadarso, M., Gómez, N., López, L.A., Tobarra, M., 2016. Calculating tourism's carbon footprint: measuring the impact of investments. Journal of Cleaner Production 111, 529 - 537. doi:https://doi.org/10.1016/j . jclepro.2014.09.019.

Caldeira, K., Davis, S.J., 2011. Accounting for carbon dioxide emissions: A matter of time. Proceedings of the National Academy of Sciences 108, 8533-8534. doi:10.1073/pnas.1106517108.

Chen, G.Q., Wu, X.D., Guo, J., Meng, J., Li, C., 2019. Global overview for energy use of the world economy: Household-consumption-based accounting based on the world input-output database (WIOD). Energy Economics 81, 835-847. doi:10.1016/j.eneco.2019.05.019. 
Chen, G.Q., Wu, X.F., 2017. Energy overview for globalized world economy: Source, supply chain and sink. Renewable and Sustainable Energy Reviews 69, 735-749. doi:10.1016/j.rser.2016.11.151.

Chen, H., Chen, G.Q., Ji, X., 2010. Cosmic emergy based ecological systems modelling. Communications in Nonlinear Science and Numerical Simulation 15, 2672-2700. doi:10.1016/j.cnsns.2009.09.025.

Chen, Z.M., Chen, G.Q., 2011. Embodied carbon dioxide emission at supranational scale: A coalition analysis for G7, BRIC, and the rest of the world. Energy Policy 39, 2899-2909. doi:10.1016/j.enpol.2011.02.068.

Chen, Z.M., Ohshita, S., Lenzen, M., 2018. Consumption-based greenhouse gas emissions accounting with capital stock change highlights dynamics of fast-developing countries. Nature Communications 9.

Davis, S.J., Caldeira, K., 2010. Consumption-based accounting of $\mathrm{CO}_{2}$ emissions. Proceedings of the National Academy of Sciences 107, 5687-5692. doi:10.1073/pnas. 0906974107.

Davis, S.J., Peters, G.P., Caldeira, K., 2011. The supply chain of $\mathrm{CO}_{2}$ emissions. Proceedings of the National Academy of Sciences 108, 18554-18559. doi:10.1073/pnas. 1107409108 .

Feng, K., Davis, S.J., Sun, L., Hubacek, K., 2015. Drivers of U.S. $\mathrm{CO}_{2}$ emissions 1997-2013. Nature Communications 6. 
Feng, K., Davis, S.J., Sun, L., Li, X., Guan, D., Liu, W., Liu, Z., Hubacek, K., 2013. Outsourcing $\mathrm{CO}_{2}$ within China. Proceedings of the National Academy of Sciences 110, 11654-11659. URL: https:// WwW . pnas.org/content/110/28/11654, doi:10.1073/pnas.1219918110, arXiv:https://www . pnas.org/content/110/28/11654.full.pdf.

Friedlingstein, P., Houghton, R.A., Marland, G., Hackler, J., Boden, T.A., Conway, T.J., Canadell, J.G., Raupach, M.R., Ciais, P., Quéré, C.L., 2010. Update on $\mathrm{CO}_{2}$ emissions. Nature Geoscience 3, 811-812. doi:10.1038/ ngeo1022.

Guan, D., Hubacek, K., Weber, C.L., Peters, G.P., Reiner, D.M., 2008. The drivers of Chinese $\mathrm{CO}_{2}$ emissions from 1980 to 2030. Global Environmental Change 18,626-634. doi:10.1016/j.gloenvcha.2008.08.001.

Hanson, K.A., Robinson, S., 1991. Data, linkages and models: US national income and product accounts in the framework of a social accounting matrix. Economic Systems Research 3, 215-232. doi:10.1080/ 09535319100000019.

Herendeen, R., 1973. An energy input-output matrix for the United States, 1963: User's guide.

Herendeen, R.A., 1978. Input-output techniques and energy cost of commodities. Energy Policy 6, 162-165. 
IEA, 2019. Total $\mathrm{CO}_{2}$ emissions: World 1990-2017. https://www.iea.org/statistics/.

IPCC, 2006. 2006 IPCC Guidelines for National Greenhouse Gas Inventories. Technical Report. Japan.

Johnson, R.C., Noguera, G., 2012. Accounting for intermediates: Production sharing and trade in value added. Journal of International Economics 86, 224-236. doi:10.1016/j.jinteco.2011.10.003.

Kanemoto, K., Lenzen, M., Peters, G.P., Moran, D.D., Geschke, A., 2012. Frameworks for comparing emissions associated with production, consumption, and international trade. Environmental Science \& Technology 46, 172-179. doi:10.1021/es202239t.

Lenzen, M., Kanemoto, K., Moran, D., Geschke, A., 2012. Mapping the structure of the world economy. Environmental Science \& Technology 46, 8374-8381. doi:10.1021/es300171x.

Lenzen, M., Moran, D., Kanemoto, K., Geschke, A., 2013. Building Eora: A global multi-region input-output database at high-country and sector resolution. Economic Systems Research 25, 20-49. doi:10.1080/09535314. 2013.769938.

Leontief, W., 1936. Quantitative input and output relations in the economic systems of the united states. The Review of Economics and Statistics 18, 105. 
Li, J.S., Chen, B., Chen, G.Q., Wei, W.D., Wang, X.B., Ge, J.P., Dong, K.Q., Xia, H.H., Xia, X.H., 2017. Tracking mercury emission flows in the global supply chains: A multi-regional input-output analysis. Journal of Cleaner Production 140, 1470-1492. doi:10.1016/j.jclepro.2016.10.002.

Li, Y.L., Chen, B., Han, M.Y., Dunford, M., Liu, W., Li, Z., 2018. Tracking carbon transfers embodied in Chinese municipalities' domestic and foreign trade. Journal of Cleaner Production 192, 950-960. doi:10.1016/j.jclepro.2018.04.230.

Liang, S., Qu, S., Zhu, Z., Guan, D., Xu, M., 2017. Income-based greenhouse gas emissions of nations. Environmental Science \& Technology 51, 346355. doi:10.1021/acs . est.6b02510.

Macworld, 2017. Where are Apple products made? https://www.macworld.co.uk/feature/apple/where-are-apple-productsmade-3633832/.

Marques, A., Rodrigues, J., Lenzen, M., Domingos, T., 2012. Income-based environmental responsibility. Ecological Economics 84, 57-65. doi:10. 1016/j.ecolecon.2012.09.010.

Meng, J., Liu, J., Xu, Y., Guan, D., Liu, Z., Huang, Y., Tao, S., 2016. Globalization and pollution: Tele-connecting local primary $\mathrm{PM}_{2.5}$ emissions to global consumption. Proc. R. Soc. A 472, 20160380. doi:10.1098/rspa. 2016.0380. 
Meng, J., Mi, Z., Guan, D., Li, J., Tao, S., Li, Y., Feng, K., Liu, J., Liu, Z., Wang, X., Zhang, Q., Davis, S.J., 2018. The rise of South-South trade and its effect on global $\mathrm{CO}_{2}$ emissions. Nature Communications 9. doi:10.1038/s41467-018-04337-y.

Mi, Z., Meng, J., Guan, D., Shan, Y., Song, M., Wei, Y.M., Liu, Z., Hubacek, K., 2017. Chinese $\mathrm{CO}_{2}$ emission flows have reversed since the global financial crisis. Nature Communications 8. doi:10.1038/s41467-017-01820-w.

Odum, H., 1983. Systems Ecology: An Introduction. John Wiley and Sons, New York.

Peters, G.P., Hertwich, E.G., 2008. $\mathrm{CO}_{2}$ embodied in international trade with implications for global climate policy. Environmental Science \& Technology 42, 1401-1407. doi:10.1021/es072023k.

Shao, L., Li, Y., Feng, K., Meng, J., Shan, Y., Guan, D., 2018. Carbon emission imbalances and the structural paths of Chinese regions. Applied Energy 215, 396-404. doi:10.1016/j .apenergy.2018.01.090.

Stone, R., 1973. A system of social matrices. Review of Income and Wealth 19, 143-166. doi:10.1111/j.1475-4991.1973.tb00879.x.

Södersten, C.J.H., Wood, R., Hertwich, E.G., 2018. Endogenizing capital in mrio models: The implications for consumption-based accounting. Environmental Science \& Technology 52, 13250-13259. 
Timmer, M.P., Dietzenbacher, E., Los, B., Stehrer, R., de Vries, G.J., 2015. An illustrated user guide to the world input-output database: The case of global automotive production. Review of International Economics 23, 575-605. doi:10.1111/roie.12178.

Tukker, A., de Koning, A., Wood, R., Hawkins, T., Lutter, S., Acosta, J., Cantuche, J.M.R., Bouwmeester, M., Oosterhaven, J., Drosdowski, T., Kuenen, J., 2013. Exiopol-Development and illustrative analyses of a detailed global Mr Ee Sut/Iot. Economic Systems Research 25, 50-70. doi:10.1080/09535314.2012.761952.

Wu, X., Guo, J., Li, C., Shao, L., Han, M., Chen, G., 2019a. Global sociohydrology: An overview of virtual water use by the world economy from source of exploitation to sink of final consumption. Journal of Hydrology 573, 794-810. doi:10.1016/j.jhydrol.2019.03.080.

Wu, X.D., Guo, J.L., Han, M.Y., Chen, G.Q., 2018. An overview of arable land use for the world economy: From source to sink via the global supply chain. Land Use Policy 76, 201-214. doi:10.1016/j.landusepol.2018. 05.005 .

Wu, X.D., Guo, J.L., Li, C., Chen, G.Q., Ji, X., 2020. Carbon emissions embodied in the global supply chain: Intermediate and final trade imbalances. Science of The Total Environment 707, 134670. doi:10.1016/j . scitotenv.2019.134670. 
889 Wu, X.D., Guo, J.L., Meng, J., Chen, G.Q., 2019b. Energy use by glob890 alized economy: Total-consumption-based perspective via multi-region 891 input-output accounting. Science of The Total Environment 662, 65-76. doi:10.1016/j.scitotenv. 2019.01.108.

Xi, J., 2017. Report of the 19th National Congress of the Communist Party of China. Technical Report. Central Committee of the Communist Party of China. Beijing.

Zhang, B., Zhang, Y., Zhao, X., Meng, J., 2018. Non- $\mathrm{CO}_{2}$ greenhouse gas emissions in China 2012: Inventory and supply chain analysis. Earth's Future 6, 103-116. doi:10.1002/2017EF000707.

Zhang, Z., Zhu, K., Hewings, G.J.D., 2017. A multi-regional input-output analysis of the pollution haven hypothesis from the perspective of global production fragmentation. Energy Economics 64, 13-23. doi:10.1016/j. eneco.2017.03.007. 